\title{
A SELF-PROPAGATING STRUCTURAL CHANGE IN TRITICUM
}

\section{Duplication and Crossing-over}

O. H. FRANKEL

Wheat Research Institute, Christchurch, New Zealand

\section{CONTENTS}

Received $4 \cdot x$ xii.48

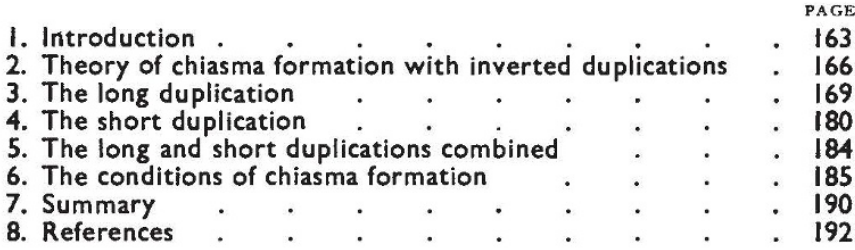

\section{INTRODUCTION}

DICENTRIC chromatids are seen at mitosis and meiosis, arising from a variety of causes. They occur at meiosis as a consequence of crossingover in inversion hybrids (Darlington, 1937) and at mitosis as a consequence of sister reunion of broken, or unbroken, ends of dividing chromosomes (D. and Upcott, I94I ; D. and Koller, I947). In anaphase a dicentric chromatid is broken by tension or cut through by the cell wall (fig. I). The point of severance may then be at the centre of the bridge $\mathrm{C}$ (median), at any point $\mathrm{X}$ between the centre and one of the centromeres (intercalary), or at one of the centromeres B (centric). Provided that broken chromosome ends are stable or " heal," the products of bridge breakage will include normal, inverted duplication and deficiency chromatids (table I).

Which types of break occur and which are functional will depend on the mechanical conditions of the bridge and of the cell, on the gene content of the duplicated-or deficient-region and on its balance relationships with the remainder of the chromosome and gene complement.

In maize $\mathrm{McClintock}$ has shown three consequences of the breakage of bridges (1938, 1939, I94I): (i) New ends of broken bridge chromatids heal, (ii) they include both duplications and deficiencies, and (iii) they vary in length. By combining genetic and cytological evidence she was able to locate breakage points with precision. She found that chromatid bridges could break anywhere along their length. Apparently, however, the breaks are more frequent near the middle of the bridge or close to a knob-presumably a point of weakness. Deficiencies in the short arm of chromosome 9, on which the majority 
of observations were obtained, are not transmitted by the pollen, and by the ovule only if they are less than one third of the length of the arm.

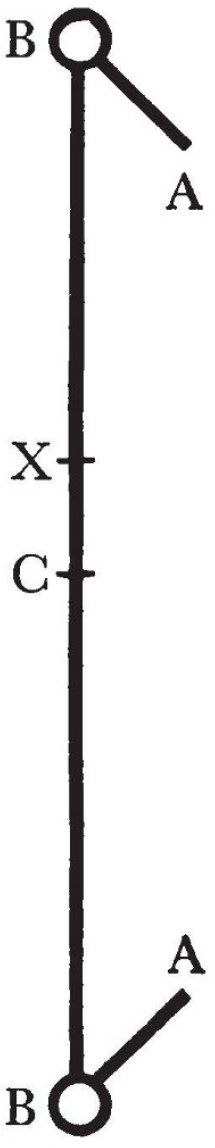

$a$

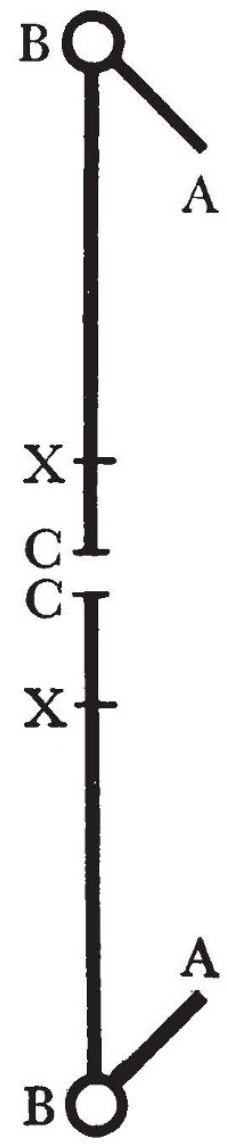

$b$

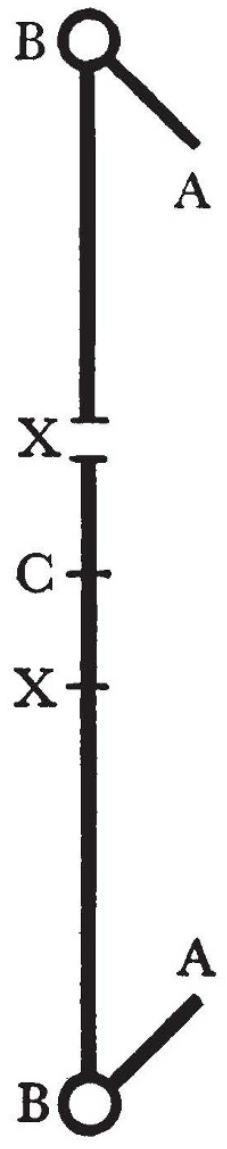

$c$

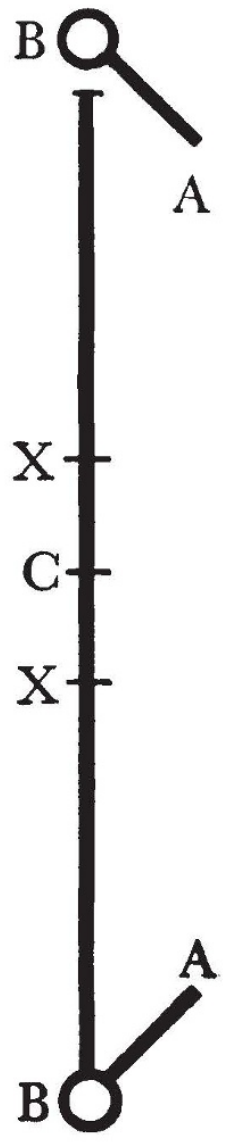

$d$

FIG. I.-Breakage types of chromatid bridges. $a$ Points of breakage. $b$ Median break.

c Submedian break. $d$ Centromere break.

TABLE I

The consequences of median, submedian and centric bridge breakage

\begin{tabular}{|c|c|c|}
\hline Position of break & Nature of chromatids & Constitution \\
\hline C & Normal & $A \cdot B \cdot X \cdot C$ \\
\hline $\mathrm{X}$ & $\begin{array}{l}\text { Inverted duplication of part of arm } \\
\text { Deficiency of part of arm }\end{array}$ & $\begin{array}{l}\text { A-B-X-C-X } \\
A-B \cdot X\end{array}$ \\
\hline B & $\begin{array}{l}\text { Inverted duplication of whole arm } \\
\text { Telocentric }\end{array}$ & $\begin{array}{l}A \cdot B \cdot X \cdot C \cdot X \cdot B \\
A-B\end{array}$ \\
\hline
\end{tabular}

Duplications, some of them long, are carried by both male and female gametes. A repetitive breakage-fusion-bridge cycle occurs in gameto- 
phyte and endosperm tissue, but ceases at fertilisation when healing takes place.

Inverted duplications such as might arise from the breakage of bridges were discovered in Triticum vulgare in I94I in the course of a study of a multiple gene change (Frankel, I950). They fell readily into two distinct classes, long and short. They belonged to the same arms, for they arise from each other and, when brought together, the arms which carry them pair.

The chromosome to which the duplications are attached is one of several of medium length with a submedian centromere; without the duplication it cannot be identified with certainty. In late diplotene (fig. 6) the long duplication repeats the whole or most of the arm to which it is attached. The relative lengths of the two types of duplications can readily be obtained from the two uncoiled fragments at anaphase II in the long-short duplication heterozygote, since these are found in the same cell and are equal the double length of the duplication (fig. I5). It is seen that the short duplication is no more than one-tenth or one-twelfth of the long one. The short duplication varies slightly in size from plant to plant, but not enough to allow classification. Between long and short, however, there is a wide gap which, according to all observations, is not bridged by intermediates.

It has been possible to obtain the full range of combinations of long-duplication, short-duplication and normal arms, including the homozygotes, heterozygotes and monosomics for these types. This provided a series varying in dosage and length of the duplicated segment, from the homozygote for the long duplication to the monosomic without a duplication :-

Description

Long/Long
Long/Normal
Long/-
Long/Short
Short/Short
Short/Normal
Short/-
Normal/Normal
Normal/-

Constitution

B-X-C-X-B/B-X-C-X-B
B-X-C-X-B/B-X-C
B-X-C-X-B/-
B-X-C-X-B/B-X-C-X
B-X-C-X/B-X-C-X
B-X-C-X/B-X-C
B-X-C-X/-
B-X-C/B-X-C
B-X-C/-

Abbreviation
$\mathrm{LD} / \mathrm{LD}$
$\mathrm{LD} / \mathrm{N}$
$\mathrm{LD} / \mathrm{O}$
$\mathrm{LD} / \mathrm{SD}$
$\mathrm{SD} / \mathrm{SD}$
$\mathrm{SD} / \mathrm{N}$
$\mathrm{SD} / \mathrm{O}$
$\mathrm{N} / \mathrm{N}$
$\mathrm{N} / \mathrm{O}$

With this series it was possible to study chiasma formation between - and within-chromosome arms both or one of which carried a duplicate sector, mirror-fashion, attached to the distal end. Such chromosomes present peculiar pairing conditions in four main respects.

First, internally (i.e. within chromosomes) the norm of longitudinal differentiation is disturbed; in its stead there is a sequence of two homologous blocks which differ from normal pairing segments in having one common distal end instead of two separate ends and centromeres. Internal pairing between these segments can be observed 
most clearly in duplication monosomics or in other types where there is no pairing between the $\mathrm{BC}$ arms.

Secondly, between chromosomes, the conditions of pairing are more complex. With respect to the duplicated sector, the pair is in fact polysomic. Yet this analogy is largely formal for the positional peculiarities impose specific pairing conditions. For example the heterozygote for the long duplication, $\mathrm{LD} / \mathrm{N}$, has three identical blocks; yet one of them has no free end but is attached to the other, the third differing from both in having a centromere and a free end. Here and even more so in the homozygote $L D / L D$ there is a choice of partners, but by no means of equal partners : they are differentiated in relation to the principal organs of attraction and movement-the centromere and the telomere.

Thirdly, between types there is the numerical differential of duplicated sectors, from two in the duplication homozygotes down to none in the normal. And finally, there is the overall differential of duplication size, allowing the distinction between the mechanical element which the duplication of an entire arm presents, and the more specific element of a very small duplicated segment.

This material was favourable in including a large range of types all of which were viable; in containing duplications of widely differing lengths; and in having a relatively low chiasma frequency. It had the disadvantage that the duplicated arm included no known marker genes. This precluded exact definition of the breakage points and necessitated cytological examination of every plant for identification, since neither duplications nor even monosomes have observable effects.

Temporary aceto-carmine preparations were used for rapid examination, permanent aceto-carmine for metaphase observations. Unless otherwise stated, text figures of anaphase I and II are from temporary, all others from permanent preparations. The terms and abbreviations, introduced on page 165 , are used throughout the paper ; but where the bivalent, the chromosome, or one of the arms is referred to in general terms, the abbreviations used are ABC bivalent or chromosome, $\mathrm{AB}$ (normal) arm and BC (duplication) arm, irrespective of the presence or absence of duplications.

\section{THEORY OF CHIASMA FORMATION WITH INVERTED DUPLICATIONS}

There are three possible kinds of chiasma formation in and between arms which carry an inverted duplication (fig. 2) :-

(I) straight, between any sectors which are common to both sister chromosomes ;

(2) internal-inverted, between the duplicated sectors within the same chromosome ; 
(3) fraternal-inverted, between the duplicated sectors of sister chromosomes.
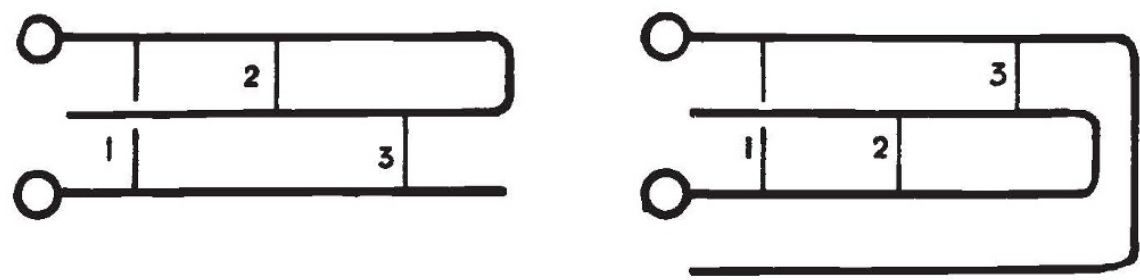

F1G. 2.-Basic chiasma types in chromosome arms heterozygous (left) and homozygous (right) for an inverted duplication. 1. straight, 2. inverted-internal, 3. invertedfraternal.

The consequences of a single chiasma of each of these types in a duplication heterozygote are illustrated in fig. 3. A straight chiasma yields normal and duplication chromatids (fig. $3 a$ ) and this is also the case for any number of straight chiasmata alone by themselves, whatever their internal relationships.
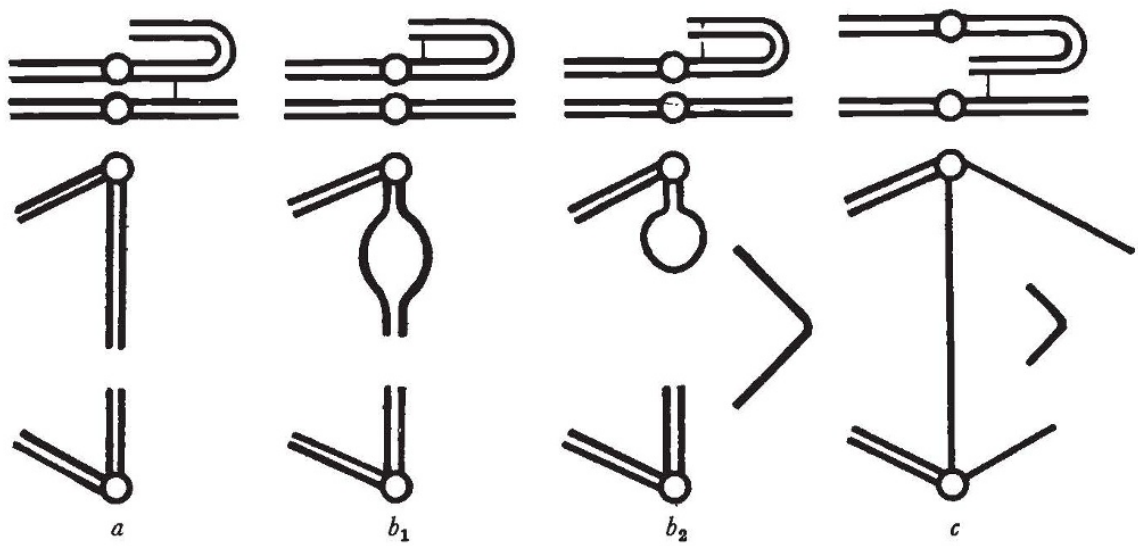

FIG. 3.-Basic chiasma types in a heterozygote for an inverted duplication. a fraternalstraight, $b_{1}$ internal, identical chromatid, $b_{2}$ internal, sister chromatid, $c$ fraternalinverted. Top pachytene, bottom anaphase $\mathrm{I}$.

Internal-inverted chiasmata can be expected to be formed in two ways : between the two sectors of an identical chromatid, or between sister chromatids. One internal chiasma of the former type yields two normal and two duplication chromatids (fig. $3 b_{1}$ ), of the latter type a loop chromatid-giving a second-division bridge, $b_{1}^{\text {ul }}$ an acentric fragment and two normal chromatids (fig. $3 b_{2}$ ) (Richardson, 1936).* I assume that chiasmata are formed between

* These expectations are based on the assumption that the union of broken ends in a duplication chiasma is as in normal chiasmata and not self-inverting. The latter would give ring chromatids from crossing-over of the same chromatid, as stipulated by Fernandes (1946, fig. 20). Such union would give ring chromatids as a result of two compensating chiasmata between two normal chromosomes, which is unheard of. Fernandes' results are probably due to an inversion within an inversion. 


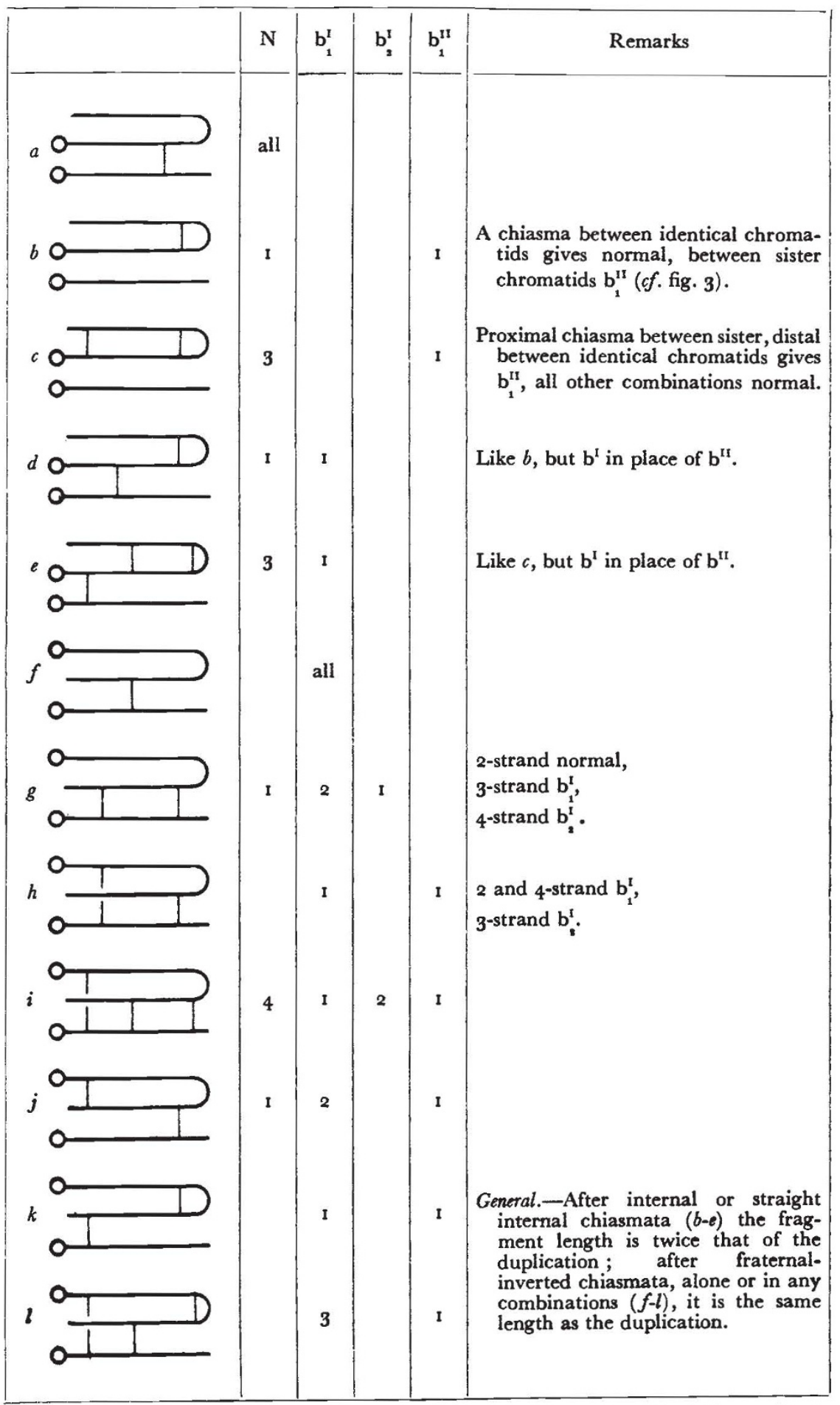

FIG. 4.-Chiasma types within and between chromosome arms one of which carries an inverted duplication. 
"identical" and "sister" chromatids with equal frequency. All preliminary expectations (figs. 4 and 5) are based on this assumption which will be tested against the data obtained.

Finally, a single fraternal-inverted chiasma gives a first-division bridge $\left(b^{1}\right)$, an acentric fragment, one normal chromatid and one with the duplication (fig. $3 c$ ) (McClintock, I94I).

These basic types are modified by multiplication or combination of chiasmata. Some simple and some more complex types of chiasma formation in heterozygotes and homozygotes are set out in figs. 4 and 5 . In spite of the great complexities of the external and internal relationships the resulting anaphase configurations fall into simple "mendelian" ratios. Some of these have characteristic features, such as the transformation by a proximal straight chiasma of $b_{1}^{\text {II }}$ in types $b$ and $c$ (fig. 4 ) to $\mathrm{b}_{1}^{\mathrm{r}}$ in types $d$ and $e$.

Widely differing types may, when combined, have identical or similar consequences. This is of particular relevance when an attempt is made to establish the presence or absence of one of the basic types of chiasma formation. It will be found that in the homozygote, combinations of straight and internal-inverted chiasmata may give the same configurations, and in some instances have the same ratios, as types with a similar number of fraternal-inverted chiasmata (e.g. $e^{\prime}$ and $g^{\prime}$, fig. 5). Hence, where there is no direct evidence of the position and number of chiasmata, preliminarily "fraternalinverted" applies to combinations of "fraternal-straight" and " internal-inverted," as well as to "fraternal-inverted" in the strict sense in which it was first introduced. This distinction is effected later.

Ratios of anaphase configurations are further modified by the combination of types which occur side by side. Diplotene observations are required; but where they cannot be relied upon, as in Triticum, and where the bivalent can be recognised, metaphase may yield information at least on the presence or absence of chiasmata in the duplication arm, at most on their number and position.

By correlating observations in metaphase I and anaphase I and II, I shall try to estimate the nature and frequency of the chiasmata which are formed in the series of duplications set out above, and from these to deduce the principles which determine the formation of chiasmata under the defined conditions of pairing which inverted duplications present.

\section{THE LONG DUPLICATION}

Owing to the great length of the long duplication the bivalent which carries it can as a rule be identified in metaphase I. This applies to both heterozygotes and homozygotes. 


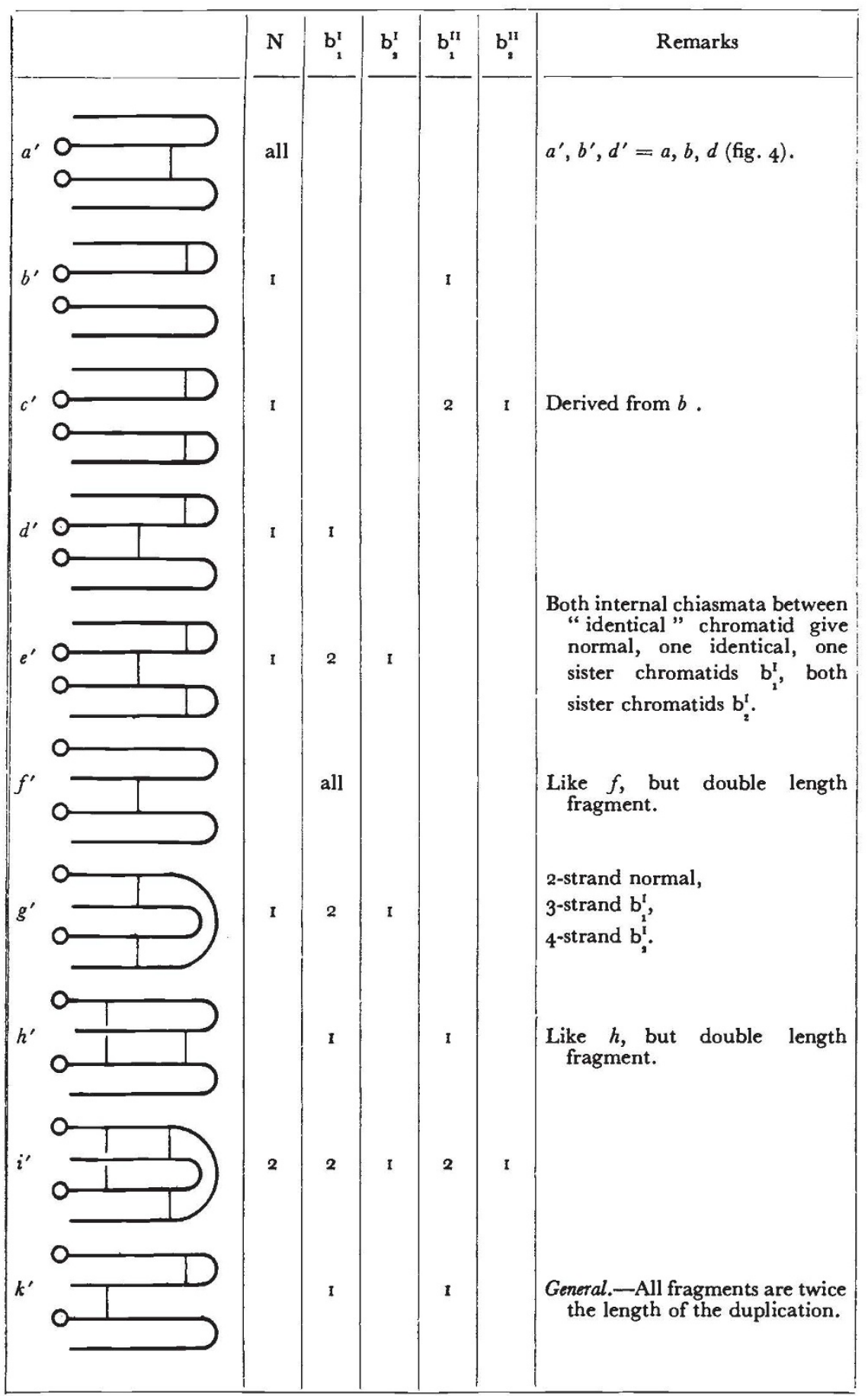

FIG. 5.-Chiasma types within and between chromosome arms both of which carry an inverted duplication. 


\section{(i) Heterozygote $L D / N$}

Diplotene is a difficult stage to analyse in Triticum. Only six cells were found in which all bivalents could be clearly seen. Internal chiasma formation was as follows :-

One chiasma near C (fig. 6a-c) . . . . . 4

One median chiasma (fig. $6 e$ ) . . . . . . I

No chiasma (fig. $6 d$ ) . . . . . . . . I

In this small sample the majority of chiasmata are distal. A visible loop occurs only once in five chiasmata.

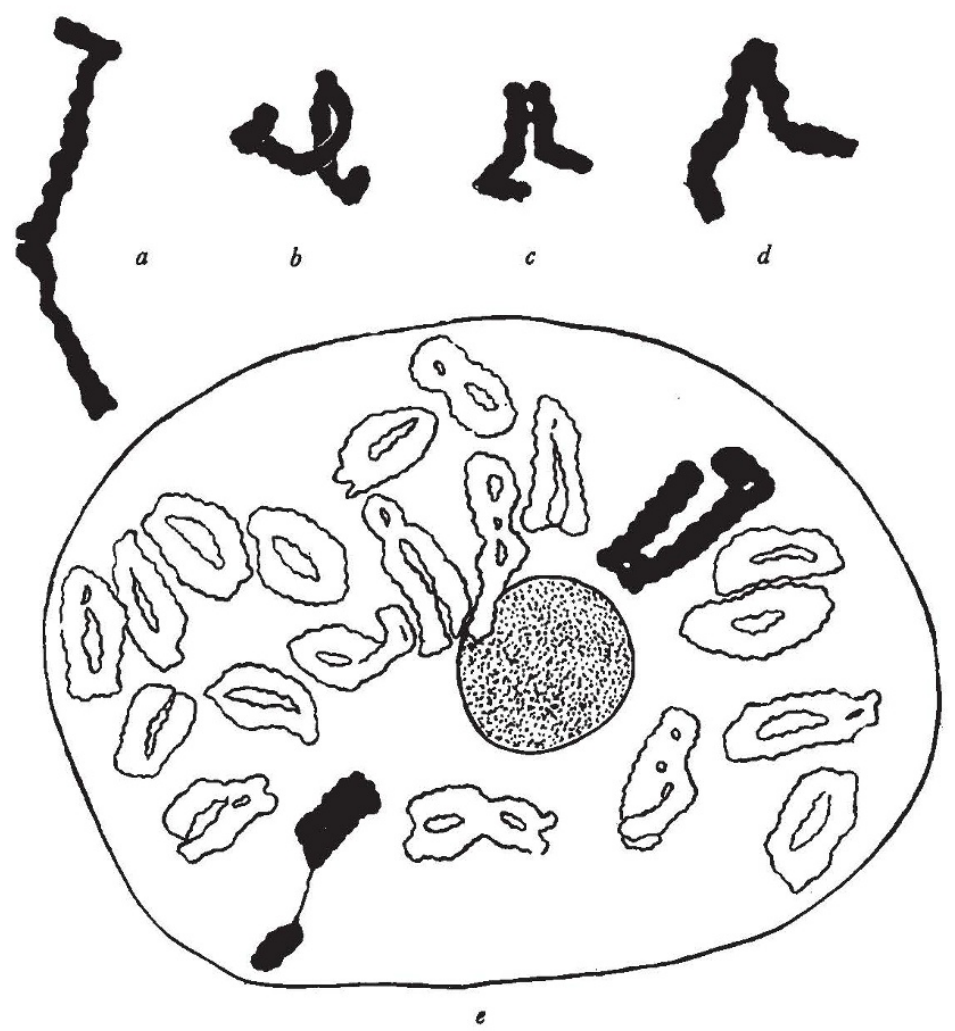

FIG. 6.-LD/N. Late diplotene. $a-c$ one internal duplication chiasma close to $\mathrm{C}$ (fig. I).

$d$ no duplication chiasma. e duplication chiasma half-way between $\mathrm{C}$ and $\mathrm{B}$, giving a loop chromosome. $e$ also shows a bivalent with a long unstained-presumably heterochromatic-segment. $\times$ I 280 .

Metaphase I.-The frequency with which the $A B C$ bivalent fails to form a chiasma is unusually high :-

Average frequency of failure of pairing (in 170 cells)
$\begin{aligned} & \text { ABC bivalent } \\ & 8 \cdot 0 \text { per cent. }\end{aligned}$

The frequent pairing failure in the duplication bivalent is doubtless due to the failure of pairing in the $\mathbf{B C}$ arm. The most common 
configuration is a bivalent with one, or less frequently with two, chiasmata in the $\mathrm{AB}$ arm, and with free $\mathrm{BC}$ arms (fig. $8 a-c$, plate I, figs. $\mathrm{I}-3$ ). In a sample of $\mathrm{I} 70$ cells, the frequency of failure of pairing in the $\mathrm{BC}$ arm was 95.3 per cent. In the remainder the $\mathrm{ABC}$ bivalent could not be identified. This may have been due either to the bivalent being "stretched out" which would render it unrecognisable ; or to one or more chiasmata in the BC arm. Subsidiary information suggesting that pairing in the BC arm is very rare or absent, comes from a comparison of cells which have only ring bivalents and no rod bivalents. In $\mathrm{LD} / \mathrm{N}$ there are no cells with ring bivalents only, but in the monosomic $\mathrm{LD} / \mathrm{O}$, which is identical for the other twenty bivalents, there were 42 per cent.

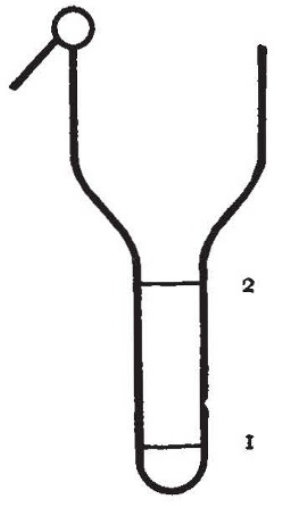

$\boldsymbol{a}$

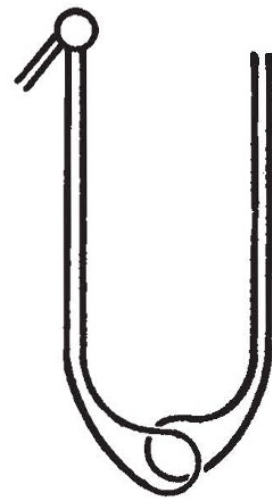

$b$

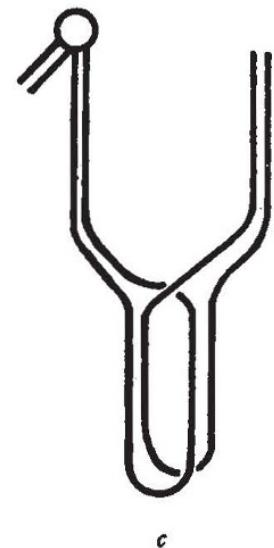

$c$

FIG. 7.-Consequences of an internal chiasma between sister chromatids ( 1 ) whether formed close to $\mathrm{C}$ ( $c f$. fig. $\mathrm{I}$ ), or (2) in a median position. $a$ pachytene, $b-c$ metaphase I. $b$ fragment breaks away, $c$ fragment locked in loop.

Internal duplication pairing is recognisable, but large loops are infrequent (fig. $8 a$, plate I, fig. 3). This is consistent with the diplotene observations; the duplication chiasma occurs mainly near the point $\mathrm{C}$, seemingly causing fragmentation of the $\mathrm{BC}$ arm (fig. $7 a, b$ ). As a rule the fragment is seen breaking off in full metaphase (fig. $7 b$, plate I, fig. 2). It seems that a chiasma within a chromosomeunlike all other chiasmata-is resolved precociously. If, however, one (or more) coils between the duplicated segments remain unresolved by the chiasma, the fragment will be locked in the loop (fig. $7 c$ ) and, especially if the fragment is long, remain so until released in the second division. The frequency of this interlocking will be a function of the distance between the chiasma and the point $\mathrm{G}$, provided coiling is the same throughout the length of the paired segment.

In fact two observations indicate that this is correct. The frequency of loop chromosomes-chromosomes with a median internal chiasmaha: been found as about 8 per cent.; and the difference between 

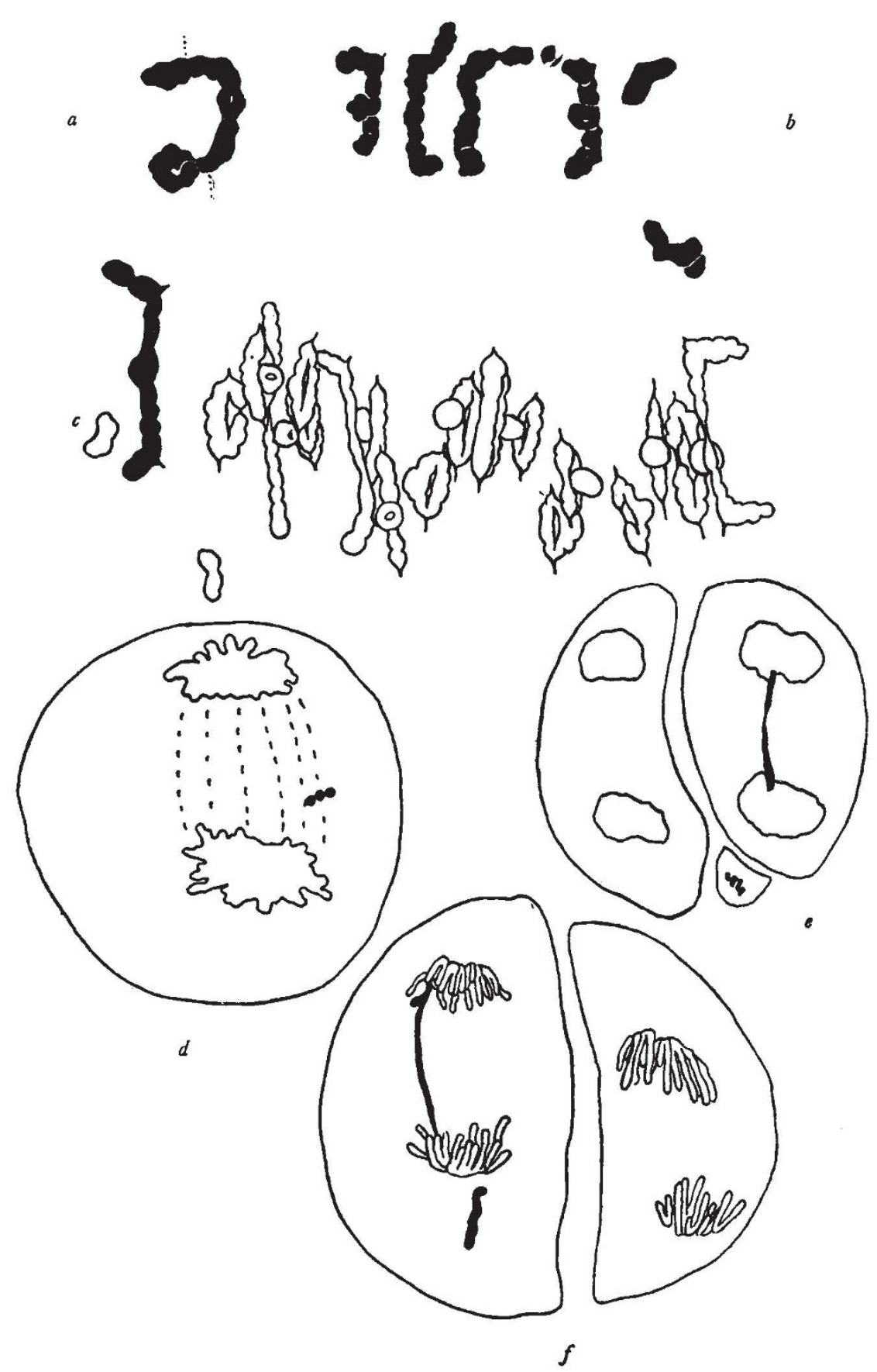

Frg. 8. - LD/N. a-c metaphase I. $a$ loop chromosome, $b$ bivalents and a pair of univalents with and without duplication chiasmata, $c$ complete cell. $d$ anaphase I, one fragment. e-f anaphase II. $e$ bridge and microcyte, $f$ bridge and free fragment. $a-c \times 1700$, d.e $\times 1120$. 
the frequencies of bridges in anaphase II and of fragments in anaphase I -presumably due to interlocking of fragments-is about 9 per cent. (see anaphase II below). It seems that when a loop chromosome is formed the fragment is locked, but when the chiasma is formed close to the point $\mathrm{C}$ the fragment is free to break away.

Anaphase I.-Apart from dividing or misdividing univalents, anaphase cells are either normal or have one long acentric fragment (fig. $8 d$ ). The loop chromatid is not often clearly seen among the twenty-one anaphase chromosomes. It is readily seen, however, when it occurs in a univalent (fig. I $2 b$ ). In the thousands of anaphase I cells examined, a first-division bridge $\left(b_{1}^{1}\right)$ was seen twice-one of these outside the count given below-and a univalent bridge (ub), resulting from internal pairing in a non-conjoined LD chromosome, once. In ro49 cells the frequencies were as follows :-

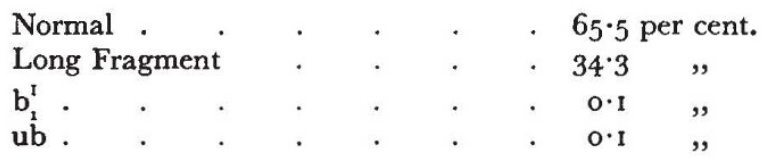

Anaphase II cells are either normal or contain one second-division bridge $\left(b_{1}^{\mathrm{II}}\right)$, resulting from the division of the centromere of a loop chromatid. The fragment is either free or is included in a microcyte $($ fig. $8 e, f)$. Frequencies, in $303 \mathrm{I}$ cells, were as follows :-

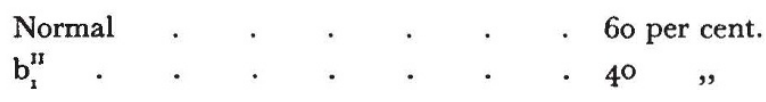

The difference from the frequency of a fragment in anaphase I $(34.5$ per cent.) is significant $(\mathrm{P}<0.00 \mathrm{I})$. It is doubtless due to some fragments remaining undetected, and interlocking between bridge and fragment has already been suggested as the cause.

Chiasma formation in the $\mathrm{LD} / \mathrm{N}$ heterozygote ( $c f$. fig. 4) may be summarised as follows :-

a. Fraternal.-Inversion pairing, alone $(f, g)$ or with a straight proximal chiasma $(h, i, j)$ is ruled out by the virtual absence of firstdivision bridges. Any fraternal pairing which occurs must be straight. Its frequency is no more than 5 per cent., but it is probably rare or absent.

$\beta$. Internal.-The frequency of second-division bridges-the result of chiasmata between sister chromatids-is 40 per cent. If, as preliminarily assumed, chiasmata between identical chromatids are equally frequent, the total internal chiasma frequency is 80 per cent. This, however, is a minimum figure ; for if two internal chiasmata occur, there are three normal cells for each cell with a bridge $(c)$. A proximal straight chiasma followed by an internal one $(d, e)$ is ruled out by the absence of $b_{i}^{i}$. 
r. Total.-

fraternal-straight - -up to 5 per cent. but probably very rare fraternal-inverted-sporadic or o

internal-inverted -8 o per cent.

\section{(ii) Homozygote LD/LD}

Metaphase I.-The most common configuration is a rod bivalent which is readily recognisable by the length of the free arms (fig. $9 a$, plate I, fig. 4); but whereas in the heterozygote pairing in the BC arm is either rare or absent, it occurs frequently in the homozygote.

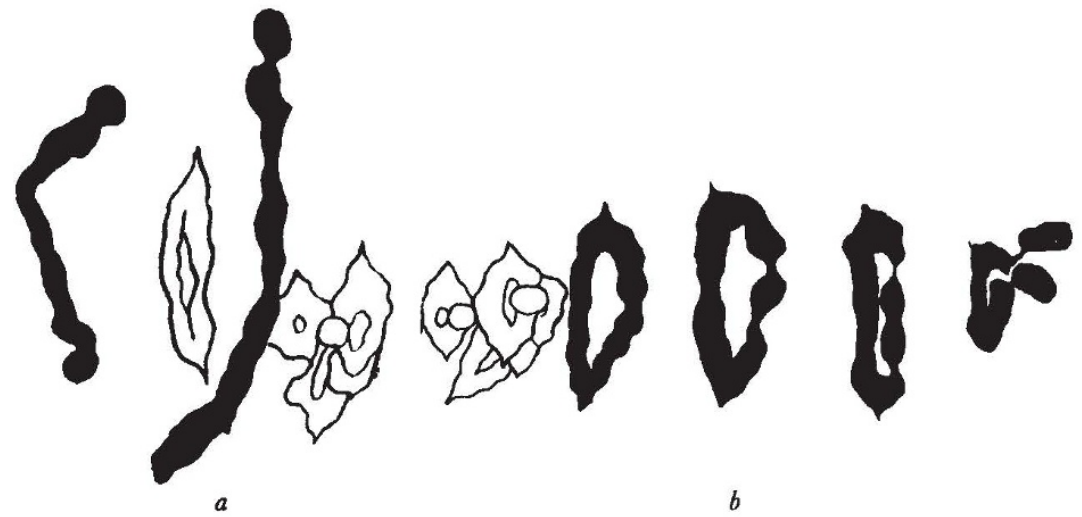

Fig. 9. - LD/LD. $a \cdot b$ metaphase I. $a$ rod bivalents; $b$ ring bivalents. $\times 1920$.

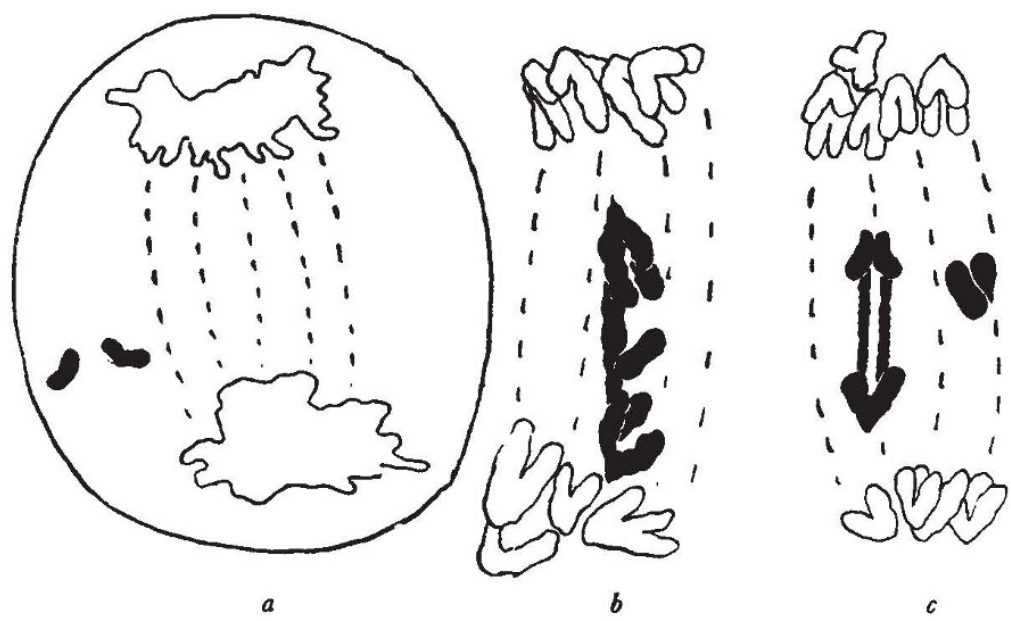

FIG. 10. $-a-c$ anaphase I. $a$ two fragments ; $b b_{1}^{1}+1 \mathrm{f} ; c b_{2}^{t}+2$ f. $a \times 1280, b, c \times 1920$.

A ring bivalent with a single loop is distinguished by its size (fig. $9 b$, plate $\mathrm{I}$, fig. 5). When the chiasma in the $\mathrm{BC}$ arm is not terminalised, there are seen two long free ends containing the duplication-an unusual bivalent type in Triticum. Sometimes this type can be 
recognised as type $f^{\prime}$, fig. $5, c f$. fig. $9 b$. A loop in the BC arm, however, would render the bivalent indistinguishable from other bivalents with two chiasmata in one arm.

Pairing frequencies in the BC arm, in 282 cells, were as follows :-

Failure of pairing in $\mathrm{BC}$ arm :-

Two ABC univalents

$\mathrm{ABC}$ rod bivalent

2 per cent.

80

Pairing in BC arm observed or inferred :-

82 per cent.

$\mathrm{ABC}$ ring bivalent $\quad \cdot \quad \cdot \quad \cdot \quad \cdot 14 \quad$ " 14

No rod bivalents, or rod bivalents other than $\mathrm{ABC} \quad 3$ "

Uncertain .

The frequency of cells without rod bivalents was 12 per cent.

Here, owing to pairing in the $\mathrm{BC}$ arm, pairing failure of the $\mathrm{ABC}$ chromosome, with a frequency of 2 per cent., is much lower than in the heterozygote. In all other bivalents it was $0 \cdot 15$ per cent., almost the same as in the heterozygote.

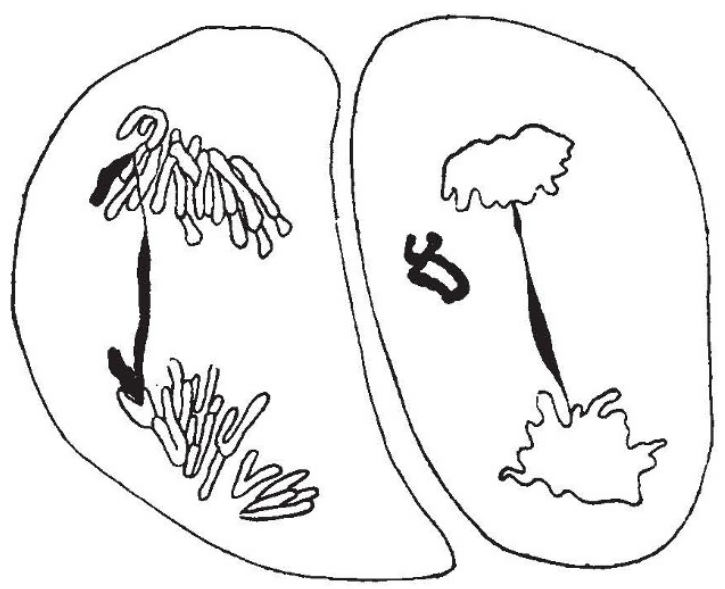

$a$

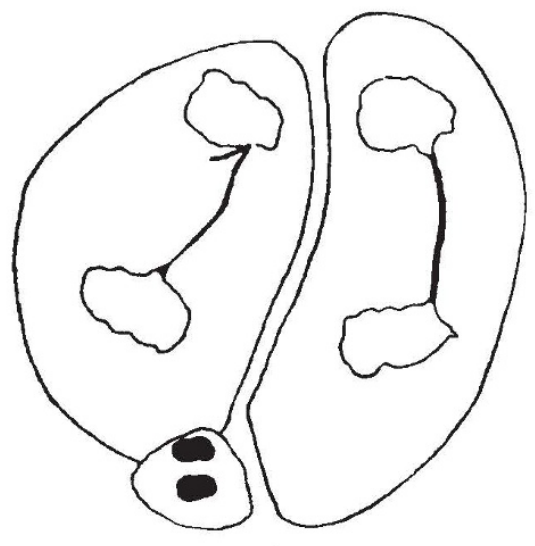

$b$

FIg. I I.-LD/LD. Anaphase II. $a \mathrm{~b}^{\mathrm{II}}+2$ free f; $b$ both fragments in microcyte. $a \times 1280$, $b \times 1120$.

Anaphase I.-The frequencies of the observed configurations in 446 cells, with the expected frequencies of the three main types calculated from those in the heterozygote, were as follows :-

\section{Observed}

Normal .

I long fragment

2 long fragments (fig. IOa)

$b_{1}^{1}+1$ long fragment (fig. $10 b$ )

$b_{2}^{1}+2$ long fragments (fig. IOc).
$42 \cdot 4$ per cent.

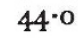

$12 \cdot 1$

$\mathrm{I} \cdot 3$

0.2

,

,
Expected

43.6 per cent.

$44^{\circ} 9$,

I I 5 , 
Anaphase II.-The frequencies of cells without, with one and with two bridges (fig. I I, plate II, fig. 4) in 1489 cells, were as follows :-

Observed

Expected from LD/N

\section{Normal \\ $39 \cdot 4$ per cent.}

b. $36 \cdot 0$

$$
\dddot{\mathrm{P}<0.001} 48 \text { " }
$$$$
16 \cdot 0 \text {, }
$$

Chiasma formation in the LD/LD homozygote ( $c f$. fig. 5) can be summarised as follows :-

a. Fraternal.-The double first-division bridges $\left(b^{\mathrm{t}}\right)$ are likely to arise from $e^{\prime}$ or $g^{\prime} ; i^{\prime}$, a more complex type derived from $e^{\prime}$, is unlikely. If there is no marked chromatid interference there will be an equal frequency of normal $\left(0.2\right.$ per cent.) and a double frequency of $b_{i}^{i}$ $(0 \cdot 4$ per cent.).

The balance of $\mathrm{b}_{1}^{x}\left(0.9\right.$ per cent.) must be due to $f^{\prime}, d^{\prime}$ or $h^{\prime}$. A bivalent which may be interpreted as $f^{\prime}$ is illustrated in fig. $9 b$. If $d^{\prime}$ bivalents occur, their frequency, without chromatid interference, is twice the frequency of $b_{i}^{x}$.

The complex types $i^{\prime}$ and $h^{\prime}$, should they occur, must be very rare.

If, as seems likely, fraternal-inverted pairing follows mainly the types $e^{\prime}$ and/or $g^{\prime}$, and $f^{\prime}$ and/or $d^{\prime}$, the tabulation of all fraternal pairing is as follows :-

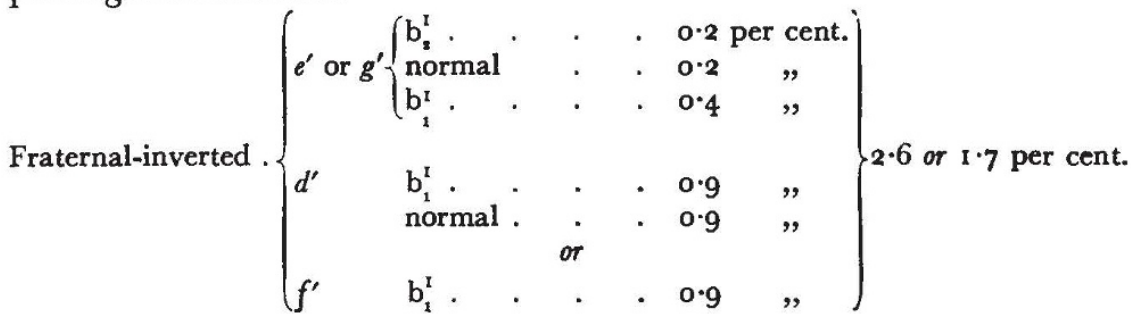

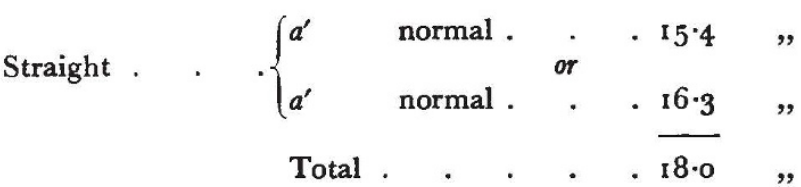

The bulk of fraternal pairing-probably nine-tenths-is straight.

$\beta$. Internal.-The frequency of $b_{1}^{\text {II }}$ and $b_{2}^{\text {II }}$ is significantly lower than in the heterozygote, but at least half of the deficiency is accounted for by fraternal inversion chiasmata.

Assuming again equal frequencies for "identical" (i) and "sister" (s) chiasmata we arrive at the following total frequencies :-

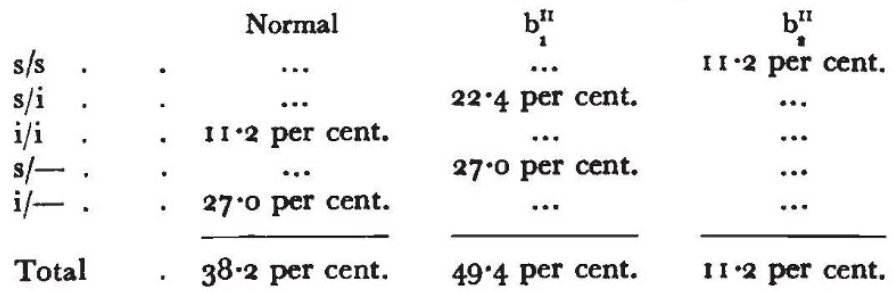


Hence the frequency of bivalents with one or two internal chiasmata is $98 \cdot 8$ per cent.

r. Total.-

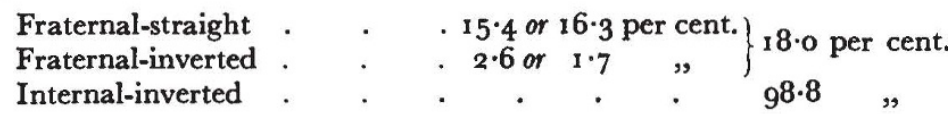

The contradiction revealed in this addition of chiasmata shows the assumption of equality for "identical" and "sister chromatid" chiasmata to be wrong. This will be discussed in the final section.

\section{(iii) Monosomic LD/O}

Metaphase I.-In all the 287 pollen mother cells examined, the univalent carrying the long duplication failed to pair with any other chromosome. The average failure of pairing per bivalent was $0 \cdot 15$ per cent., which we have already found in the heterozygote and the homozygote. The frequency of cells without rod bivalents was 42 per cent. As in the heterozygote, loop pairing in the inverted duplicated region is occasionally seen (fig. I $2 a$ ).

Anaphase I.-Where no duplication chiasma is formed, the univalent either goes undivided to one pole, or it divides, or it misdivides. When a chiasma occurs, the univalent again goes to one pole, forming a loop chromatid and an acentric fragment (fig. I2 $b$ ) or it divides, forming a univalent bridge and a fragment (fig. I $2 c, d$ ). Univalent bridges are formed when the centromere of a loop chromatid

TABLE 2

The consequences at first and second division of chiasma formation in the univalents of the monosomics $L D / O$ and $S D / O$

\begin{tabular}{|c|c|c|c|c|c|c|c|c|}
\hline \multicolumn{3}{|c|}{ Anaphase I } & \multicolumn{3}{|c|}{ Anaphase II } & \multicolumn{3}{|c|}{$\begin{array}{c}\text { Inferred } \\
\text { Duplication chiasmata }\end{array}$} \\
\hline Behaviour & $\mathrm{LD} / \mathrm{O}$ & $\mathrm{SD} / \mathrm{O}$ & Behaviour & $\mathrm{LD} / \mathrm{O}$ & $\mathrm{SD} / \mathrm{O}$ & & $\mathrm{LD} / \mathrm{O}$ & $\mathrm{SD} / \mathrm{O}$ \\
\hline undivided & $38 \%$ & $36 \%$ & normal & & & & & \\
\hline $\begin{array}{l}\text { divided } \\
\text { misdivided }\end{array}$ & $\begin{array}{r}15 \% \\
7 \%\end{array}$ & $\begin{array}{r}15 \% \\
3 \%\end{array}$ & $\begin{array}{l}\text { normal, or } \\
\text { lagging }\end{array}$ & $67 \%$ & $71 \%$ & no $X$ & $60 \%$ & $54 \%$ \\
\hline $\begin{array}{l}u b+f \\
l o o p+f\end{array}$ & $\begin{array}{r}7 \% \\
33 \%\end{array}$ & $\begin{array}{l}17 \% \\
29 \%\end{array}$ & $b_{1}^{11}$ & $33 \%$ & $29 \%$ & $\mathrm{x}$ & $40 \%$ & $46 \%$ \\
\hline
\end{tabular}

divides in anaphase I (Upcott, I937). This occurs sporadically in bivalents as a consequence of non-conjunction, but should occur frequently when a regularly unpaired chromosome has relatively inverted homologous sections in the same arm. Since the univalent is isolated on the equator when its centromere divides and its duplication chiasma is resolved, these processes are more readily observed than in a bivalent (figs. 12 and 14). Similarly, breakage of the 

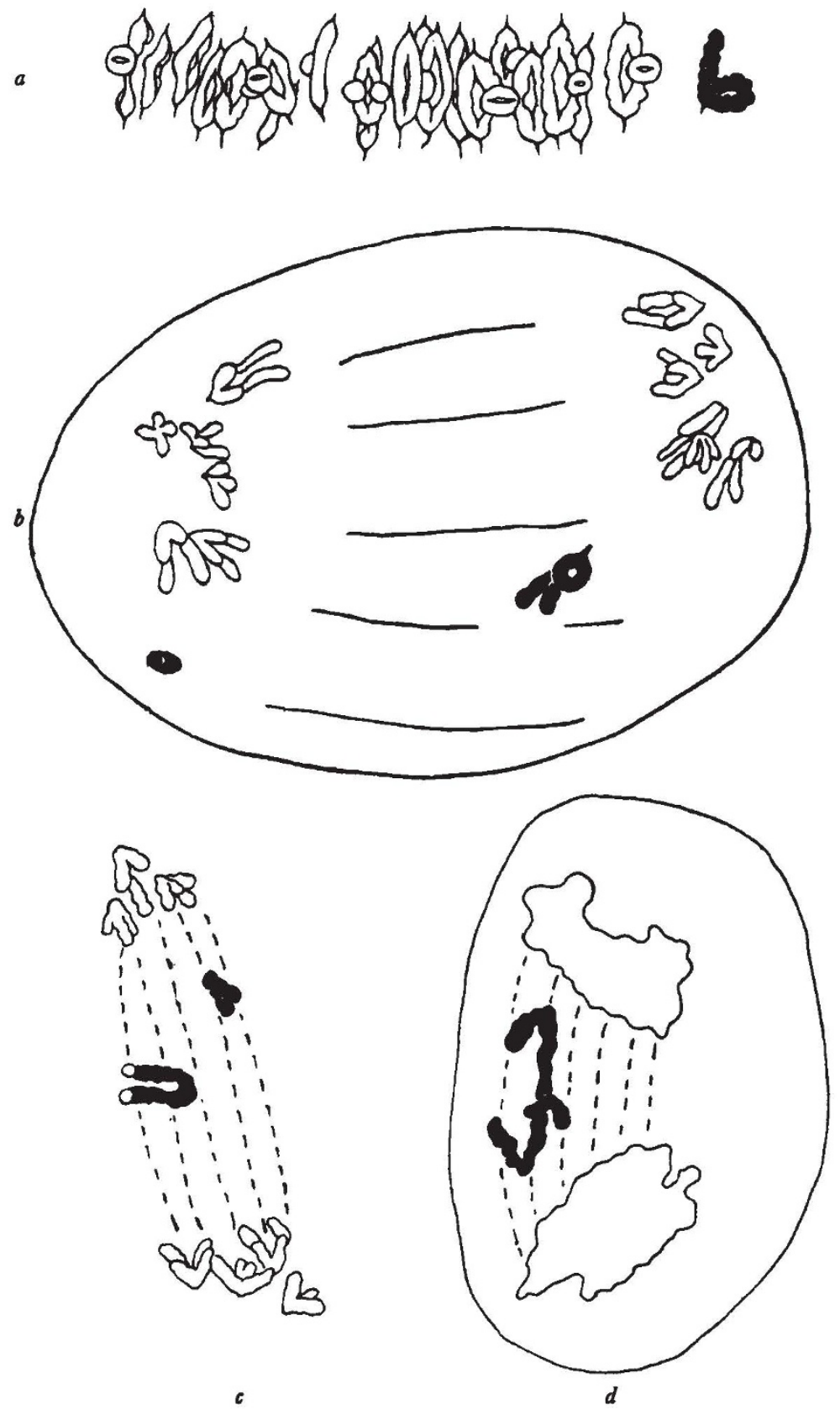

Fig. 12.-LD/O. $a$ metaphase I, loop chromosome. $b$-d anaphase I. $b$ loop chromatid and fragment ; $c$ incipient, and $d$ developed univalent bridge. $c$ and $d$ permanent aceto-carmine. $\times 1700$. 
univalent bridge is more clearly observable than that of the second anaphase bridge. It was found that as a rule a univalent bridge breaks at or near its centre, or, rarely, at or near one of the centromeres, as happens occasionally in first-division bridges. A bridge broken in this manner yields a chromatid with a long inverted duplication and possibly a telocentric. The relevance of these observations for the origin of the long and short inverted duplications is discussed in the second paper of this series.

The frequencies of anaphase I configurations, in 265 cells, and of the corresponding anaphase II configurations, in 722 cells, are given in table 2. The correspondence is complete; so is also that of the frequencies of internal pairing in the monosomic and in the heterozygote.

\section{THE SHORT DUPLICATION}

Owing to the small size of the short duplication, metaphase chromosomes which carry it are recognisable only when associated with the acentric fragment on the point of breaking away (fig. 13). Similarly, fragment frequencies in anaphase I are doubtful. The only reliable test of chiasma frequencies is the number of first- and seconddivision bridges.

\section{(i) Heterozygote SD/N}

Metaphase-Anaphase I.-We have seen that the long duplication restricts or inhibits pairing with the corresponding arm of a normal chromosome. The short duplication should provide a test whether this inhibition is mainly mechanical or specific. Since the ABC bivalent cannot be reliably identified, less direct evidence on chiasma formation in the $\mathrm{BC}$ arm has to be used. This derives from three sources:-

(I) Failure of pairing in the $\mathrm{ABC}$ bivalent. Observations in I Io cells are recorded below, in comparison with the observations in the long-duplication heterozygote ; figures in italics are calculated :-

Failure of pairing in duplication heterozygotes

\begin{tabular}{llll} 
& \multicolumn{2}{c}{$\mathrm{LD} / \mathrm{N}$} & \multicolumn{2}{c}{$\mathrm{SD} / \mathrm{N}$} \\
$\mathrm{ABC}$ bivalent &. & $8 \cdot 00$ per cent. & 1.60 per cent. \\
Other 20 bivalents &. & $0.17 \%$ & $0.15 \quad$ *
\end{tabular}

(2) Frequency of bivalents with free BC arms. In I Io metaphase cells, none were found without at least one bivalent with one arm unpaired. When compared with $3^{\mathrm{I}}$ per cent. of cells without rod bivalents in the monosomics, and $2 \mathrm{I}$ per cent. in normal sister plants, this suggests restricted pairing in the arm carrying the short duplication.

(3) Frequency of fraternal-inverted pairing. Only three cells with a bridge were found among the many hundreds of cells examined in anaphase I. This shows that, as in the heterozygote for the long duplication, fraternal-inverted pairing is very rare or absent.

* Average of LD/N (O.1 7 per cent.) and LD/LD, LD/O and SD/O (o.15 per cent.). 
I conclude that the short duplication restricts pairing with a normal arm, though possibly less so than the long duplication, and that, since fraternal-inverted pairing can be no more than sporadic, any fraternal pairing which occurs is straight.

Anaphase II.-The frequencies of second-division bridges in 3046 cells were as follows :-

$$
\begin{aligned}
& \text { Normal . . . . . . } 67 \cdot 9 \text { per cent. } \\
& \mathrm{b}_{1}^{\mathrm{n}} \text {. }
\end{aligned}
$$

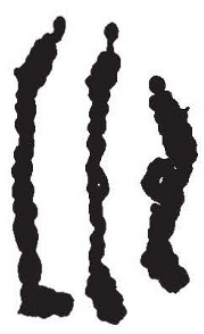

$a$

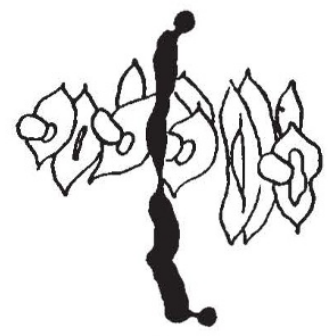

$b$
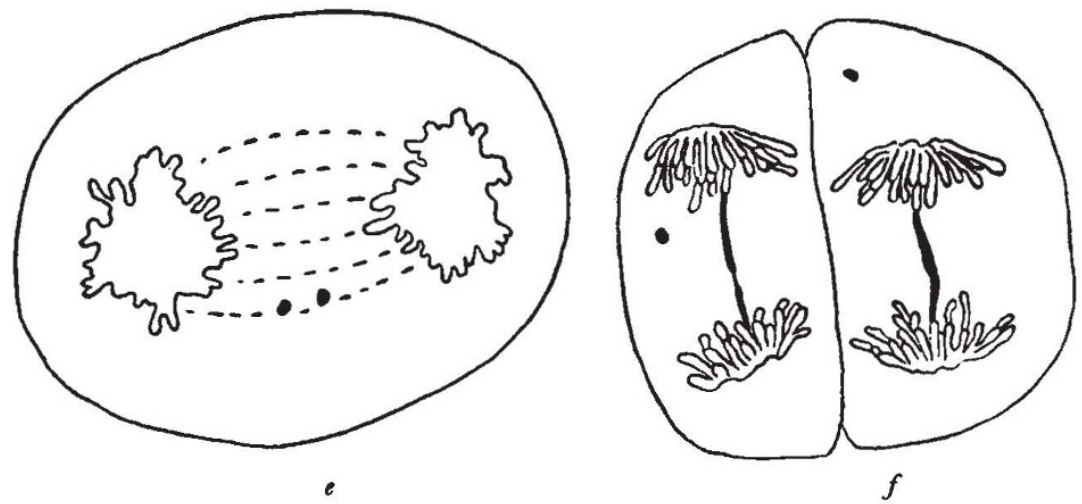

Fig. 13. $-a \mathrm{SD} / \mathrm{N}$. Metaphase I. Rod bivalents, short fragment breaking away. $b \cdot f$ $\mathrm{SD} / \mathrm{SD}$. $b-c$ metaphase $\mathrm{I}$, rod and ring bivalents. $d-e$ anaphase $\mathrm{I}$. $d \mathrm{~b}_{2}^{1}+2 \mathrm{f}$; e 2f. $f$ anaphase II, $\mathrm{b}_{2}^{\mathrm{II}}+2 \mathrm{f}$. $a, b, d \times 1700, c \times 2300, e, f \times 1120$.

The difference from 40 per cent., the frequency of bridges in the long-duplication heterozygote, is significant $(\mathrm{P}<0 \cdot 001)$.

Chiasma formation in the $\mathrm{SD} / \mathrm{N}$ heterozygote may be summarised as follows :-

Fraternal-straight - probably very rare

Fraternal-inverted-sporadic or none

Internal-inverted $-64 \cdot 2$ per cent. 


\section{(ii) Homozygote SD/SD}

Metaphase I.--The average frequency of failure of pairing of the $\mathrm{ABC}$ bivalent was 2 per cent.; that of the other twenty bivalents $0 \cdot$ I 5 per cent.

The pairing frequency of the $\mathrm{BC}$ arm cannot be directly ascertained since the bivalent cannot as a rule be recognised. It is estimated as follows : The frequency of cells with ring bivalents only is 19 per cent. in $\mathrm{SD} / \mathrm{SD}$, against 12 per cent. in $\mathrm{LD} / \mathrm{LD}$. In the latter the frequency of $\mathrm{ABG}$ ring bivalents was ascertained as 18 per cent. Applying the same ratio to $\mathrm{SD} / \mathrm{SD}$, the frequency of chiasmata in the $\mathrm{BC}$ arm is calculated as $28 \cdot 5$ per cent.

Anaphase I.-Frequencies of first-division bridges, in 170 cells, were as follows :-

\begin{tabular}{llll} 
No bridges &. & & \multicolumn{3}{c}{$89 \cdot 6$ per cent. } \\
$\mathrm{b}_{1}^{\mathrm{I}}+\mathrm{If}$ (plate II, fig. 3) &. &. & $7 \cdot 8 \quad "$ \\
$\mathrm{~b}_{2}^{\mathrm{1}}+2 \mathrm{f}$ (plate II, figs. I and 2) &. &. & $2 \cdot 6 \quad "$
\end{tabular}

Anaphase II.-The frequencies of the three expected classes, in 1399 cells, were as follows :-

\section{Normal}

Observed . . . . $52 \cdot 3$ per cent.

Expected from $\mathrm{SD} / \mathrm{N}$. . $46 \cdot \mathrm{I} \quad$,

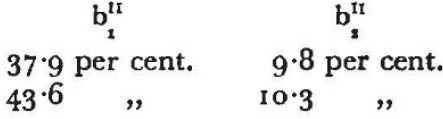

37.9 per cent. $\quad 9.8$ per cent. $43 \cdot 6 \quad$ 10.3

Chiasma formation in the SD/SD homozygote ( $c f$. fig. 5) may be summarised as follows :-

a. Fraternal.-The tabulation for fraternal chiasma formation, calculated as in $\mathrm{LD} / \mathrm{LD}$, is as follows :-

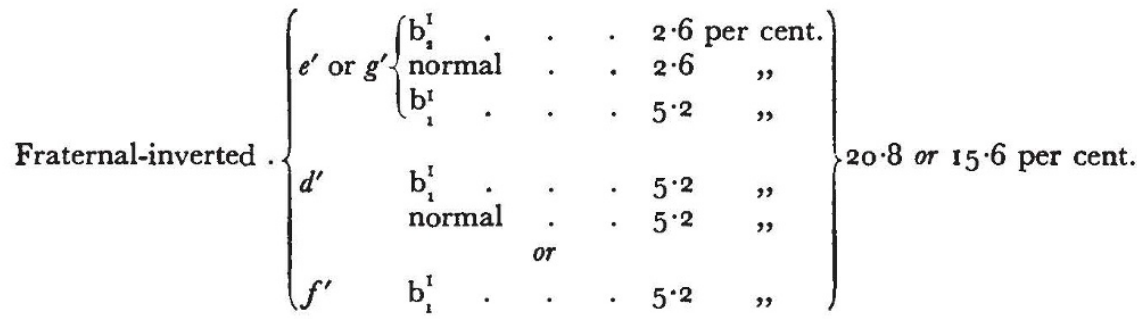

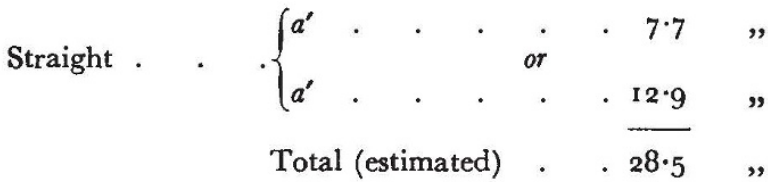

B. Internal.-The deficiency of $b^{n}$ is more than compensated by $b^{1}$, resulting from fraternal-inversion pairing. If the frequency of "identical" chiasmata is equal to that of "sister" chiasmata, the total chiasma frequency is $75^{\circ} \cdot 8$ per cent. 
r. Total.-

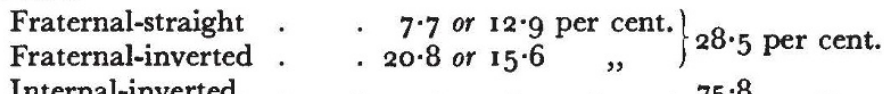

Internal-inverted . . . . . . . $75 \cdot 8$,

\section{(iii) Monosomic SD/0}

Metaphase I.-The univalent does not pair with any other chromosome. An additional pair of univalents has the normal frequency of 0.15 per cent.

Anaphase I and II.-The same configurations were found as in the long-duplication monosomic (fig. I4 and table 2). Since the acentric fragment resulting from duplication crossing-over is very small, the frequency of chiasma formation in undivided univalents could not be established directly; instead it was derived from the frequency of second-division bridges.

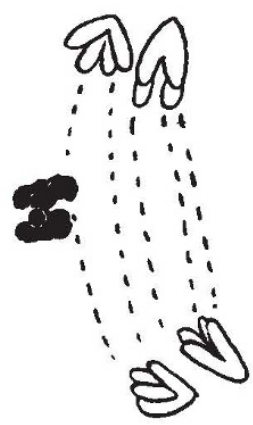

$a$

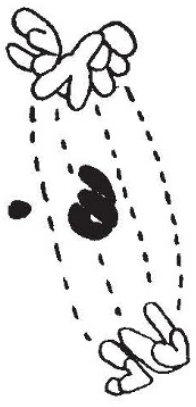

$b$

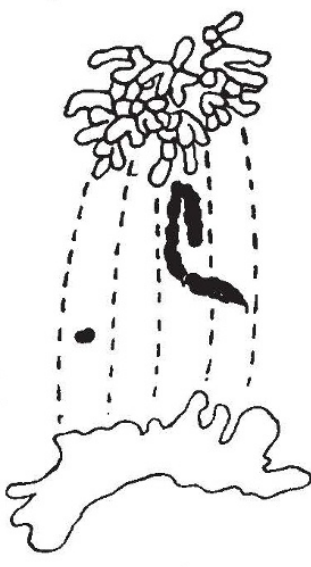

$c$

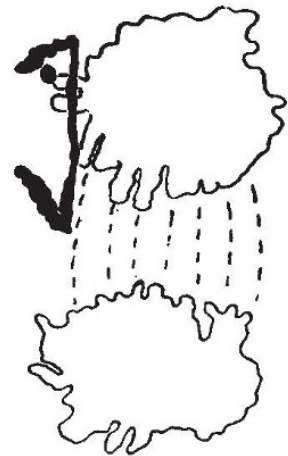

$d$

Frg. 14.-SD/O. Development of univalent bridge. $a \times 1$ 700, $b-d \times 1470$.

The frequency distribution, obtained from the examination of 432 anaphase I and 943 anaphase II cells, is given in table 2. The chiasma frequency is higher in the monosomic with the short duplication than in that with the long one, in marked contrast from the corresponding heterozygotes :-

\begin{tabular}{|c|c|c|c|c|c|c|c|c|c|}
\hline & & & & Heter & gotes & & Mon & mic & \\
\hline & & & & Long & Short & & ong & & \\
\hline ub & . & . & . & $\ldots$ & $\ldots$ & & cent. & 17 & cent. \\
\hline$b_{1}^{11}$ & $\cdot$ & - & $\cdot$ & 40 per cent. & $3^{2}$ per cent. & 33 & " & 29 & ", \\
\hline & & & $\cdot$ & 40 & $3^{2}$ & 40 & ", & 46 & , \\
\hline
\end{tabular}

Univalent bridges are more than twice as frequent when the duplication is short than when it is long. This, it seems, is partly due to the greater mobility of an SD monosome which will facilitate orientation in the equator of the cell, partly to the higher frequency of misdivision in the LD monosome. 


\section{THE LONG AND SHORT DUPLICATIONS COMBINED (LD/SD)}

Metaphase and Anaphase I.--In the majority of cells the unequal bivalent can be recognised either as a rod bivalent with unequal free arms (fig. $15 a$ ) or as a ring bivalent (fig. $15^{b}$ ). The ABC pair always formed a bivalent ; the average failure of pairing in the other twenty bivalents was also lower than in the other types ( $0 \cdot 05$ per cent.).

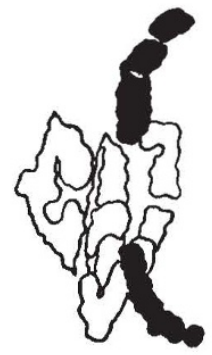

$a$

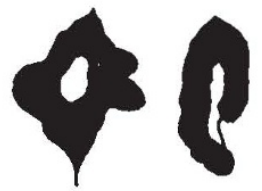

$b$

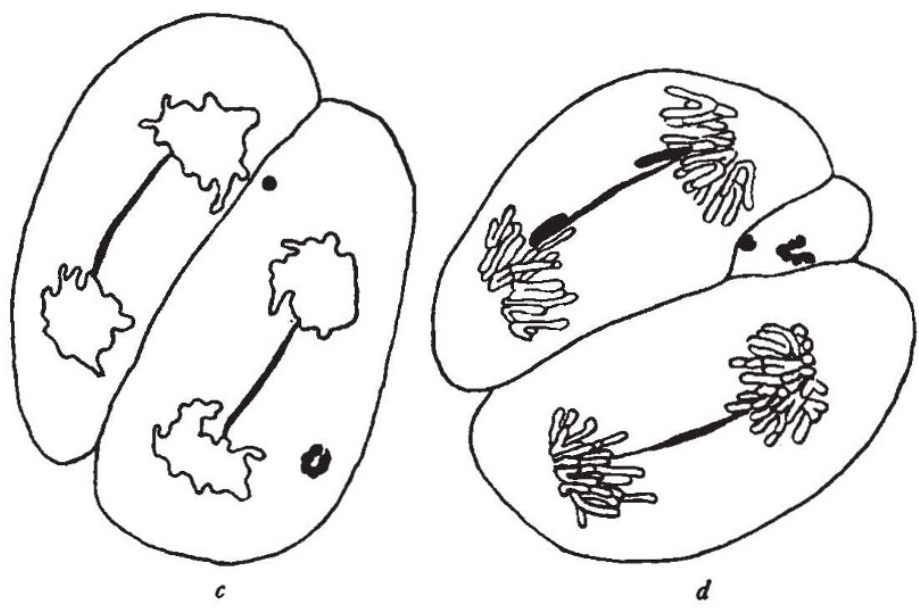

FIG. 15.-LD/SD. $a \cdot b$ metaphase I. Rod and ring bivalents. $c-d$ anaphase II. $c \mathrm{~b}^{\mathrm{II}}+2$ free $\mathrm{f}, d$ both fragments in microcyte. Note long and short fragments in same cell. $a-b \times 1700, c-d \times 1120$.

Evidence on the frequency of fraternal pairing comes from the following observations on rgo cells :-

Failure of pairing in $\mathrm{BC}$ arm : $\mathrm{ABC}$ rod bivalent . . . . 88 per cent.

Pairing in BC arm observed or inferred :-

Cells without rod bivalents . . . . . 7 per cent.

Cells with rod bivalents, none of which is $\mathrm{ABC} \quad .2$ "

Cells with rod bivalents, $\mathrm{ABC}$ identified as ring bivalent 3 ",

It is thus established that pairing occurs, with a frequency of 12 per cent., between arms one of which carries the long, the other the short duplication. 
Anaphase observation shows that all pairing is straight, since among many hundreds of cells examined there was only one $b_{1}$. Fraternal-inversion pairing-if it occurs at all-is as rare as in the heterozygotes with normal.

Anaphase II.-Since short fragments cannot be counted reliably, the frequency of bridges alone is given (in 494 cells) :-

Normal $\quad b_{1}^{\text {II }} \quad b_{3}^{\text {II }}$

Observed . . . . . 38.9 per cent. 48.6 per cent. 12.5 per cent. Expected from heterozygotes with $40.9,46.1$, 13.0 " normal

$$
\mathbf{P}<0.8
$$

Chiasma formation in the combined heterozygote LD/SD ( $c f$. figs. 4 and 5) may be summarised as follows :-

a. Fraternal.-Since there are no first-division bridges, the only type of fraternal chiasma which occurs in the heterozygote for both duplications consists of one (or possibly more) straight chiasmata, without internal pairing in the same bivalent $\left(a^{\prime}\right)$.

$\beta$. Internal.-In the combined heterozygote the observed frequency is in close agreement with that calculated from the component frequencies. This is at variance with the ratios in the homozygotes, but consistent with the occurrence of fraternal-inversion pairing in the latter and its absence in the former. The total chiasma frequency including "identical" chiasmata, calculated as for the homozygotes, is $97 \cdot 2$ per cent.

$\gamma$. Total.-

Here, as in the homozygote $L D / L D$, we find proof that the assumption of equality for "identical" and "sister chromatid" chiasmata is wrong. This will be discussed further.

\section{THE CONDITIONS OF CHIASMA FORMATION}

\section{(a) Internal}

(i) Internal pairing.-Conditions of internal pairing are peculiar. Here the first condition of pairing, attraction of homologous partners, is fulfilled a priori. Inside pairing in inverted duplications, as in isochromosomes (Darlington and Janaki-Ammal, I945), has thus a natural advantage. It is therefore not surprising that the frequency of inside pairing, even in the short duplication, is high.

(ii) Identical vs. sister chromatid chiasmata.-So far the assumptions have been made (I) that chiasmata between the two duplicated sections of the same chromatid occur, and (2) that they have the same frequency as those between sister chromatids whose frequency is 
revealed by that of second-division bridges. It is now possible to examine the validity at least of the second assumption.

TABLE 3

Chiasma frequencies in duplication heterozygotes and homozygotes

\begin{tabular}{|c|c|c|c|c|c|}
\hline \multirow[b]{2}{*}{ Type } & \multicolumn{2}{|c|}{ Internal } & \multicolumn{3}{|c|}{ Fraternal } \\
\hline & $\begin{array}{c}\mathrm{b}^{\mathrm{II}} \text { frequency } \\
\text { (bivs. giving } \\
\mathrm{b}^{\mathrm{II}} \text { ) }\end{array}$ & $\begin{array}{l}\text { X frequency } \\
\text { (" ident.", } \\
\text { " sister") }\end{array}$ & Inverted & Straight & Total \\
\hline $\begin{array}{l}\mathrm{LD} / \mathrm{N} \\
\mathrm{SD} / \mathrm{N} \\
\mathrm{LD} / \mathrm{SD} \\
\mathrm{LD} / \mathrm{LD} \\
\mathrm{SD} / \mathrm{SD}\end{array}$ & $\begin{array}{l}40 \cdot 0 \% \\
32 \cdot 1 \% \\
61 \cdot 1 \% \\
60 \cdot 6 \% \\
47 \cdot 7 \%\end{array}$ & $\begin{array}{l}80 \cdot 0 \% \\
64 \cdot 2 \% \\
97 \cdot 2 \% \\
98 \cdot 8 \% \\
75 \cdot 8 \%\end{array}$ & $\begin{array}{l}\text { o } \\
\text { o } \\
0 \\
1 \cdot 7 \% * \\
15 \% 6 \%\end{array}$ & $\begin{array}{c}\text { probably very rare } \\
\text { rare } \\
12 \cdot 0 \% \\
16 \cdot 3 \% \\
12 \cdot 9 \%\end{array}$ & $\begin{array}{c}\text { probably very rare } \\
\text { rare } \\
12 \cdot 0 \% \\
18 \cdot 0 \% \\
28 \cdot 5 \%\end{array}$ \\
\hline
\end{tabular}

* Pairing types $f^{\prime} \cdot g^{\prime}$, fig. 5

Column 2 in table 3 contains the frequencies of chiasmata estimated on the basis of equality between sister and identical chromatid sections. These frequencies, combined with those of the fraternal chiasmata, must not exceed roo per cent. : for coincidence of fraternal and internal chiasmata transforms $\mathrm{b}^{\mathrm{II}}$ into $\mathrm{b}^{\mathrm{I}}$ (fig. $5, d^{\prime}, e^{\prime}$ ). The only one of the three types which satisfies this condition is $\mathrm{SD} / \mathrm{SD}$. Here the excess over too per cent. is small and subject to the uncertainty of the estimate for total pairing frequency. In the $\mathrm{LD} / \mathrm{LD}$ and $\mathrm{LD} / \mathrm{SD}$ types, however, the addition produces an excess of 16.8 per cent. in the former, 9.2 per cent. in the latter. This proves that chiasmata between sections of the same chromatid, if they occur, are less frequent than those between sister chromatids.

We see then that crossing-over between chromatids of a chromosome arm paired with itself is not at random : there is chromatid interference across the "bend." In general this is not the case where identical and relatively inverted segments are joined at the centromere, as in attached X chromosomes in Drosophila (Beadle and Emerson, 1935, and Weinstein, 1936), although in some instances there are indications of chromatid interference across the centromere (Bonnier and Nordenskiöld, 1937). On the whole it seems, however, that there is a continuity of chromosome organisation which is broken by a centromere, but prevails under the peculiar conditions of pairing of an arm with itself.

(iii) Bridge frequencies in heterozygotes and homozygotes.-If allowance is made for $\mathbf{b}^{1}$ frequencies in the homozygotes, the frequencies of internal chiasmata in the homozygotes are consistent with the assumption of independent internal chiasma formation in the two partner chromosomes. This is most clearly shown in the combined heterozygote where no first-division bridges occur. 
(iv) Chiasma frequency and length of duplication.- The internal chiasma frequency in the short duplication is four-fifths of that in the long one ; its length is no more than one-tenth. Chiasma frequency is only. weakly correlated with chromosome length. This indicates that chiasma formation is localised in the region where normal arm and duplication join. This, as previously shown, is confirmed by direct observation in diplotene and metaphase.

\section{(b) Fraternal (Table 3, columns 3-5)}

(i) Duplication/Normal.-A terminal inverted duplication severely restricts, and perhaps inhibits, chiasma formation with a normal arm. If such chiasmata are formed they must be of the straight type. The evidence is suggestive-but not conclusive-that the size of the duplication affects the intensity of this inhibition. The inhibition is due to the presence of the duplication, but not specifically to a chiasma in it ; for in the homozygotes, where internal chiasmata per bivalent have a much higher frequency, fraternal pairing is not inhibited.

(ii) Duplication/Duplication.-When a duplication is attached to both chromosomes, pairing takes place, in the order :-

$$
\mathrm{SD} / \mathrm{SD}>\mathrm{LD} / \mathrm{LD}>\mathrm{LD} / \mathrm{SD}
$$

(iii) Direction of pairing.-Fraternal-inverted chiasmata are absentor, with the order of $\mathrm{r} / 500-\mathrm{r} / \mathrm{rooo}$, merely sporadic-in all three heterozygotes. In the homozygote $\mathrm{LD} / \mathrm{LD}$ they are about one-tenth, in $\mathrm{SD} / \mathrm{SD}$ at least one-half of all fraternal chiasmata.

(iv) Nature of inverted pairing.- - It has been pointed out before that true fraternal-inverted chiasmata (fig. 5, $f^{\prime}$ and $g^{\prime}$ ) cannot be distinguished from combined straight and internal-inverted chiasmata $\left(d^{\prime}\right.$ and $\left.e^{\prime}\right)$ by their effects on anaphase configurations alone. This is equally true if chiasmata between identical chromatids are few or absent; types $d^{\prime}$ and $e^{\prime}$ occurring together will be indistinguishable from $f^{\prime}$ and $g^{\prime}$.

This difficulty of distinction is overcome, however, when the duplication series as a whole is subjected to comparative analysis. If $d^{\prime}$ and $e^{\prime}$ occur in LD/LD and SD/SD, no reason can be seen why either or both should fail to occur in LD/SD; but this, as we have seen, is in fact the case : there are no inversion chiasmata in paired arms if the two duplications are not the same. This makes it clear that when two arms, each carrying a duplication, cross over, inversion chiasmata in one partner are not independent of those in the other, as they are when the arms are unpaired. It suggests that inversion pairing is different in paired and unpaired arms. In the latter, of necessity, it is always within chromosomes and hence independent; in the former, it seems, it is always, or prevailingly, between chromosomes, and hence dependent. We conclude that what has been referred to as true fraternal-inverted pairing $\left(f^{\prime}\right.$ and $\left.g^{\prime}\right)$ is the main or perhaps the only type of inversion crossing-over between chromosomes. 
(v) Conditions of fraternal pairing.-The analysis of fraternal chiasmata suggests a two-fold specificity of pairing behaviour. Chiasma formation is strongly restricted-or altogether inhibited-if one chromosome carries a duplication and the other does not; but it is restored if both ends are equipped with duplications, though even of different lengths. This suggests a specificity of chromosome ends : "duplication ends" pair, but there is no pairing between "nonduplication" and "duplication ends." * Whatever the nature of the difference, it is of overriding importance, of greater importance in fact than the relative length of the pairing arms or even the genetic relationship of the terminal segments.

This specificity of attractions, however, is not a universal characteristic of duplication and non-duplication chromosomes. There is no evidence that it occurs in maize, where fraternal-inversion chiasmata between duplication and normal arms are frequent (McClintock, 194I). Triticum, as Darlington (1931, 1940) has shown, has proterminally localised chiasmata, hence chromosome ends have a particular function in the initiating of pairing. A comparative study of the pairing behaviour in both genera may shed further light on the nature of the difference; but the difficulties of prophase observation in wheat are a serious obstacle.

There is, however, a further relevant difference. Maize is a diploid with ten bivalents, wheat a hexaploid with twenty-one: chromosome movement in wheat, in comparison with maize, must be greatly restricted. Yet this alone does not provide a full explanation; for duplication homozygotes in wheat form inversion chiasmata.

In wheat, as we have seen, the specificity of chromosome ends controls all kinds of pairing; but inversion pairing demands the additional specificity of pairing lengths. Pairing takes place only if the duplications are identical ; and, contrary to the norm, it is the more frequent the shorter are the pairing segments (table 3 , column 3 ). This indicates specific pairing modes consistent with our assumption of reciprocal types of inversion pairing in the homozygotes. Their intricate patterns require a high degree of precision in the alignment of pairing units, achieved, one may presume, by polarisation. In this process the requirement of effort-or time-will be proportional with the length of the duplication, in fact with the "drag" of the extra lengths to be reciprocally aligned.

\section{(c) General (fig. 16)}

Pairing in the Triticum duplications reveals the following principles :-

(i) Bridges and fragments of the expected types are found.

* This cannot be due to differences in heterochromatin, since hexaploid wheat, unlike rye (Levan, 1942), has no heterochromatic segments. None are visible in the resting nucleus, nor is there any differential staining after cold treatment. 
(ii) Internal pairing predominates over fraternal pairing, as in isochromosomes (A-E I).

(iii) Fraternal-inversion pairing takes place only if the arms are equal (A-E 4 ), since pairing is expected to begin at the ends.

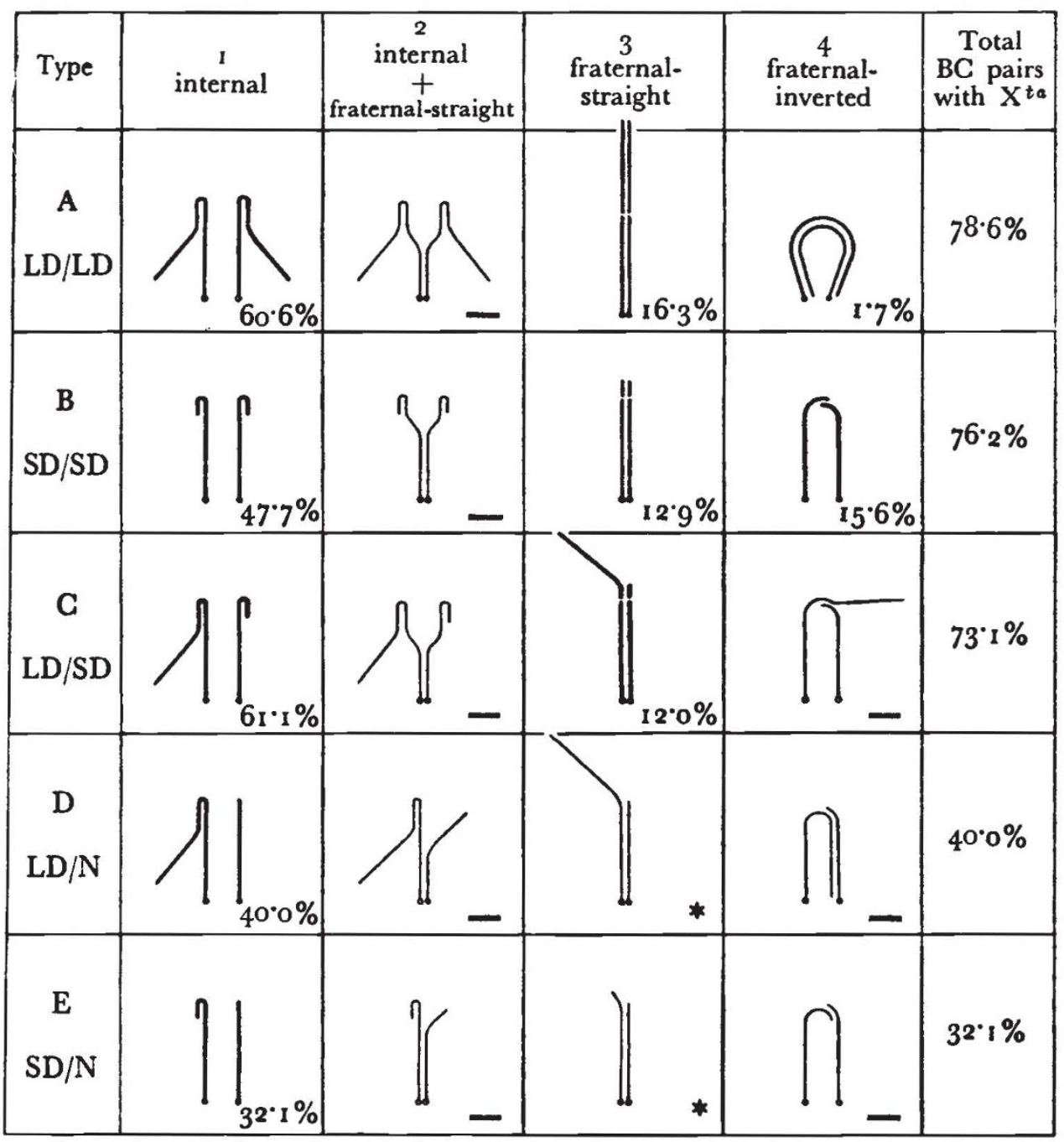

Fig. 16.-Pairing types in homozygotes and heterozygotes for inverted duplications, which occur (heavy lines) and fail to occur (thin lines) in wheat ; $\mathrm{D}_{3}$ and $\mathrm{E}_{3}\left(^{*}\right)$ are rare. $\mathrm{D}_{4}$ occurs in maize. Pairing frequencies are given in percentages of cells; frequencies of internal pairing are the frequencies of crossovers between sister-chromatids.

(iv) Two duplications, of whatever length, when not internally paired, may hinder, but not block fraternal pairing (A-C 3 ).

(v) One or both duplications, when internally paired, block pairing between arms $\left(A-C_{2}\right)$ : there are no changes of partner. This reveals 
a pairing interference between "terminal" and "centric" pairing. Pairing starts either terminally, i.e. in the duplication, or near the centromere, but, unlike pairing in some species of Fritillaria (Frankel, 1940), not in both at the same time. This interference is scarcely a result of competition between the two. For this the critical configuration is $\mathrm{B}_{2}$ : duplication (i.e. terminal) pairing is confined to less than one-tenth of the possible pairing length, yet there is no centric pairing. Here is revealed what seems to be a new principle of pairing.

(vi) One duplication, whether internally paired or unpaired, blocks fraternal pairing with an arm without a duplication (D-E 2-4). This reveals a specificity of attraction between duplication and non-duplication ends.

\section{SUMMARY}

I. Terminal inverted duplications occur as a consequence of non-median rupture of chromatid bridges. Such duplications were found in derivatives of a varietal cross in Triticum vulgare. A "long" duplication probably duplicates the entire arm to which it is attached. The "short" duplications in the same arm vary slightly in length; they are no more than one-tenth of that of the long duplication.

2. Homozygotes, heterozygotes and the combined heterozygote long/short were obtained. Forty-one-chromosome plants (monosomics) of long, short and normal were also found.

3. The expected consequences of chiasma formation in duplication heterozygotes and homozygotes with crossing-over within and/or between chromosomes are shown (figs. 4 and 5).

4. Internal chiasma formation (within chromosome arms) occurs in all types. It is localised near the union between the duplicated segments and hence chiasma frequency is only loosely correlated with duplication length. It is more frequent between sister chromatids than within the same chromatid-if the latter occurs at all ; there is chromatid interference across the "bend."

5. Fraternal chiasma formation (between chromosomes) is severely restricted, or absent, in the heterozygotes duplication/normal. It occurs, however, in ascending order of frequency, in the heterozygote long/short and in the homozygotes long/long and short/short.

6 . The general principles of fraternal pairing are summarised in the final section. Fraternal-inversion pairing occurs only between equal arms. Duplications, one or both of which are paired internally, block fraternal pairing - there are no changes of partner. Duplications, when not paired internally, hinder fraternal pairing without blocking it entirely; but one duplication alone blocks pairing with an arm without a duplication: there is a specificity of attraction between duplication and non-duplication ends.

In a second paper I shall present evidence on the transmission and evolutionary history of the inverted duplications. 
Acknowledgments.-The manuscript of this paper was concluded during a visit to the John Innes Horticultural Institution, London. I am greatly indebted to Dr C. D. Darlington, F.R.S., for granting me the facilities of the Institution, and for valuable criticisms and suggestions. My colleagues Mrs S. W. Boyce and Messrs L. G. L. Copp and T. P. Palmer made many of the preparations used in this study.

\section{Appendix \\ THE DETERMINATION OF CELL-WALL FORMATION}

Darlington (1936) suggested that after the separation of the chromosomes in anaphase, the centromeres are not only responsible for further chromosome movement, but that they control the formation of the cell wall; hence in an anaphase rendered atypical by a lagging univalent, the cell wall may be modified through deflection to both sides of the univalent so that it becomes enclosed in a microcyte. This should not occur, however, in the case of an acentric fragment. Observations in Tulipa confirmed these conclusions (Upcott, 1937). In the diploids where all fragments are acentric, no microcytes are found whereas they occur in triploids which contain both acentric fragments, resulting from inversion crossing-over, and lagging univalents.

That acentric fragments may form microcytes, however, has been shown by Frankel (1937) in diploid species of Fritillaria. Here acentrics, resulting from crossingover in an inversion, not uncommonly form microcytes. Upcott (loc. cit.) concludes from this observation that in certain circumstances body repulsions may bring about cell-wall deflection. The frequency, number and variety of acentric fragments observed in the present study permit further and more specific conclusions.

In the inverted duplication types, lagging univalents and centric fragments resulting from misdivision are rare in comparison with acentric fragments resulting from chiasma formation in the duplication, as is shown by the very low frequency of microcytes in the normal monosomic. On the other hand, in the duplication types, where acentric fragments are frequent, both free fragments and microcytes are found regularly (figs. 9, I I, 13, I5 and table 4).

TABLE 4

Percentages of fragments and microcytes in plants differing in size and number of acentric fragments. S short fragment, L long fragment; f free fragment, (f) or (ff) microcyte

\begin{tabular}{|c|c|c|c|c|c|c|c|}
\hline Fragment content & $f$ & (f) & ff & $f(f)$ & (ff) & $(f)(f)$ & Number of cells \\
\hline $\begin{array}{l}\text { S } \\
\text { L } \\
\text { SS } \\
\text { LS } \\
\text { LL }\end{array}$ & $\begin{array}{c}9^{8 \cdot 1} \mathbf{1} \\
64 \cdot 5 \\
\ldots \\
\ldots \\
\ldots\end{array}$ & $\begin{array}{c}\mathrm{r} \cdot 9 \\
35 \cdot 5 \\
\ldots \\
\ldots \\
\ldots\end{array}$ & $\begin{array}{c}\ldots \\
\ldots \\
92 \cdot 7 \\
59 \cdot 7 \\
55 \cdot 7\end{array}$ & $\begin{array}{c}\ldots \\
\ldots \\
2 \cdot 9 \\
21 \cdot 0 \\
11 \cdot 0\end{array}$ & $\begin{array}{c}\ldots \\
\ldots \\
4 \cdot 4 \\
19 \cdot 3 \\
31 \cdot 7\end{array}$ & $\begin{array}{l}\ldots \\
\cdots \\
\cdots \\
\cdots \\
\mathrm{r} \cdot 2\end{array}$ & $\begin{array}{r}1902 \\
2291 \\
\mathrm{r} 37 \\
62 \\
167\end{array}$ \\
\hline
\end{tabular}

* $\mathrm{S}(\mathrm{L})$

That acentric fragments may cause cell-wall deflection in Triticum is clear; but what are the factors which determine whether deflection takes place, i.e. whether a microcyte is formed?

Direct observation indicates the position of the fragment as the first condition. A cell wall is deflected only by a body directly in its plane of formation; this, one may assume, is equally true of centric and acentric laggards.

A statistical survey shows the size of the lagging body as the second determining factor. The frequencies of free fragments and microcytes in cells containing one 
or two short or long fragments are shown in table 4. It is readily seen that the short fragment, single or double, induces far fewer microcytes than the long fragment. Convincing proof comes especially from a comparison of microcyte frequencies where short and long fragments occur side by side in the same plant, viz. in the heterozygote, LD/SD. Here the frequencies for the free and enclosed long fragmeni were respectively 60.5 per cent. and 39.5 per cent., and correspondingly for the short fragment, 97.5 per cent. and 2.5 per cent.

An analysis of the full range of fragments permits more precise comparisons. Pooling the frequencies of microcytes irrespective of whether one or both fragments present are included, we arrive at the following series of microcyte frequencies :-

S

SS

L

LS

LL

1.9 per cent. $\quad 7.3$ per cent. $\quad 35.5$ per cent. $\quad 40 \cdot 3$ per cent. $\quad 44.3$ per cent.

Clearly the larger the lagging mass, the greater the chance of its obstructing the cell wall. A further illustration comes from a comparison of $f(f)$, where only one fragment lies in the plane of the cell wall, and (ff), where both fragments are in the critical position, for SS, LS and LL. As might be expected, (ff) is more frequent than $f(f)$ where the size difference between one and two fragments is substantial ; two present a larger target than one. Hence in SS and LL, (ff) is far more frequent than $f(f)$. But in $L S$, where $f(f)$ invariably is $S(L)$, the addition of the small fragment makes little difference to the target size; hence frequencies for $f(f)$ and (ff) are the same.

Darlington and Upcott (1941) observed the movement of acentric fragments in pollen grain divisions of Tulipa. Here acentric chromatids resulting from the same break usually attract each other and hence are found in close proximity. The case of two acentric fragments derived from crossing-over in different arms is distinct both as to origin and nature of the fragments, especially where they differ in size. Yet there can be little doubt that these also attract each other. Evidence of this is the very rare occurrence of long fragments in separate microcytes, viz. $1 \cdot 2$ per cent., against $f(f)$ with $11 \cdot 5$ per cent. and (ff) with $31 \cdot 7$ per cent. In LD/SD, the short fragment alone has a microcyte frequency of 2.5 per cent. but when a large fragment is also present, the microcyte frequency of the short fragment is increased eightfold through its association with the long one.

\section{SUMMARY}

Cell walls are formed round acentric fragments provided the latter are lying in the plane of wall formation. The larger the obstacle the fragment or fragments present, the higher the frequency of microcytes.

\section{REFERENCES}

BEADLE, G. W., AND EMERSON, S. 1935 .

Further studies of crossing-over in attached $\mathrm{X}$ chromosomes in Drosophila melanogaster. Genetics, 20, 192-206.

BONNIER, G., AND NORDENSKIÖLD, M. 1937.

Studies in Drosophila melanogaster with attached X's. I. Crossing-over values. Frequencies of reciprocal and non-reciprocal changes. Chromatid interference.

Hereditas, 33, 257-278.

DARIINGTON, C. D. I93I.

The analysis of chromosome pairing in Triticum hybrids.

Cytologia, 3, 21-25. 
DARLINGTON, c. D. 1936 .

The external mechanics of the chromosomes.

P.R.S., B., I2I, 264-319.

DARLINGTON, C. D. $\quad$ I937.

Recent Advances in Cytology. 2nd ed. London.

DARLINGTON, C. D. 1940.

The prime variables of meiosis.

Biol. Rev., 15, 307-322.

DARLINGTON, C. D., AND JANAKI-AMMAL, E. K. $\quad$ I 945 .

Adaptive isochromosomes in Nicandra.

Ann. Bot., 9, 267-281.

DARLINGTON, C. D., AND KOLLER, P. C. 1947.

The chemical breakage of chromosomes.

Heredity, I, 187-221.

DARLINGTON, C. D., AND UPCOTT, M. B. I94I.

Spontaneous chromosome change.

J. Genet., 4I, 297-338.

FERNANDES, A. 1946 .

Sur le comportement des chromosomes surnuméraires hétérochromatiques pendant la méiose. I. Chromosomes longs hétérobrachiaux.

Bol. Soc. Broteriana, 20, 93-I 54 .

FRANKEL, O. H. 1937 .

Inversions in Fritillaria.

7. Genet., 34, 447-462.

FRANKEL, O. H. I940.

The causal sequence of meiosis. I. Chiasma formation and the order of pairing in Fritillaria.

7. Genet., 41, 9-34.

FRANKEL, O. H. I950.

A polymeric multiple gene change in hexaploid wheat.

Heredity, 4 (in the press).

LEVAN, A. 1942.

Studies on the meiotic mechanism of haploid rye.

Hereditas, 28, 1 77-21 1 .

MCLINTOCK, B. 1938.

The fusion of broken ends of sister half-chromatids following chromatid breakage at meiotic anaphases.

Missouri Agr. Exp. Sta. Res. Bull., 2go, 1-48.

MCLINTOCK, B. 1939 .

The behaviour in successive nuclear divisions of a chromosome broken at meiosis.

Proc. Nat. Acad. Sci., 25, 405-416.

McCLINTOCK, B. 1941 .

The stability of broken ends of chromosomes in Zea Mays.

Genetics, 26, 234-282.

RICHARDSON, M. M. I 936 .

Structural hybridity in Lilium Martagon album $\times$ L. Hansonii.

7. Genet., 32, 4I I -450. 
UPCOTT, M. 1937.

The external mechanics of the chromosomes. VI. The behaviour of the centromere at meiosis.

P.R.S., B., 124, 336-36r.

WRINSTEIN, A. 1936.

The theory of multiple-strand crossing over.

Genetics, 2I, 1 55-199. 
Plate I.-Pollen mother cells at metaphase I. $\times$ ca. ${ }_{1} 500$.

Fig. 2.-LD/N. Internal chiasma, fragment breaking away.

FIG. 1.-LD/N. No internal chiasmata.

FIG. 4.-LD/LD. Two internal chiasmata, both fragments breaking away.

Fig. 3.-LD/N. Loop chromosome.

Fig. 5.-LD/LD. Ring bivalent (on left of plate). 

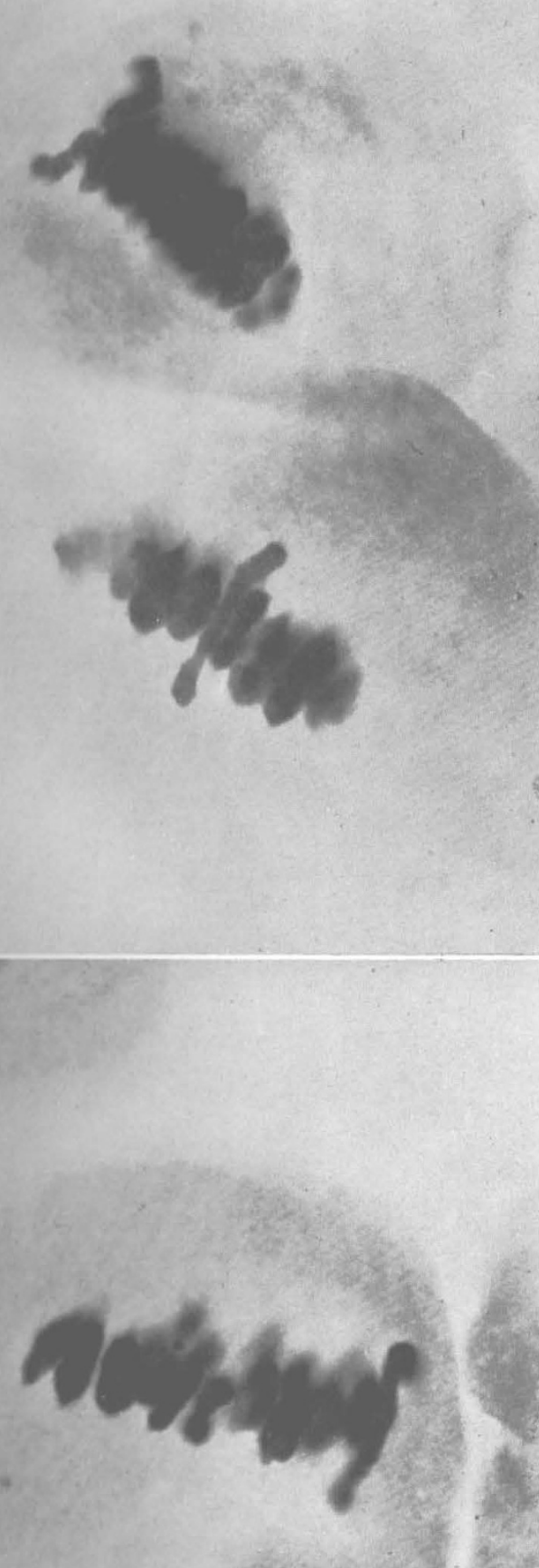

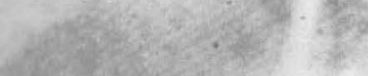
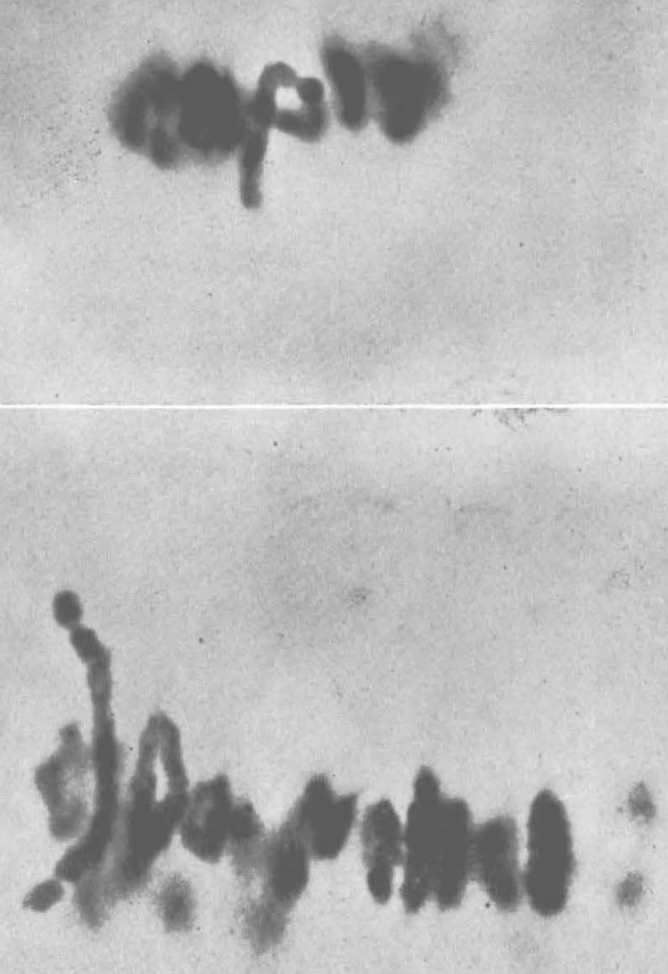

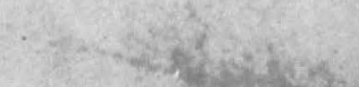

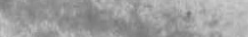

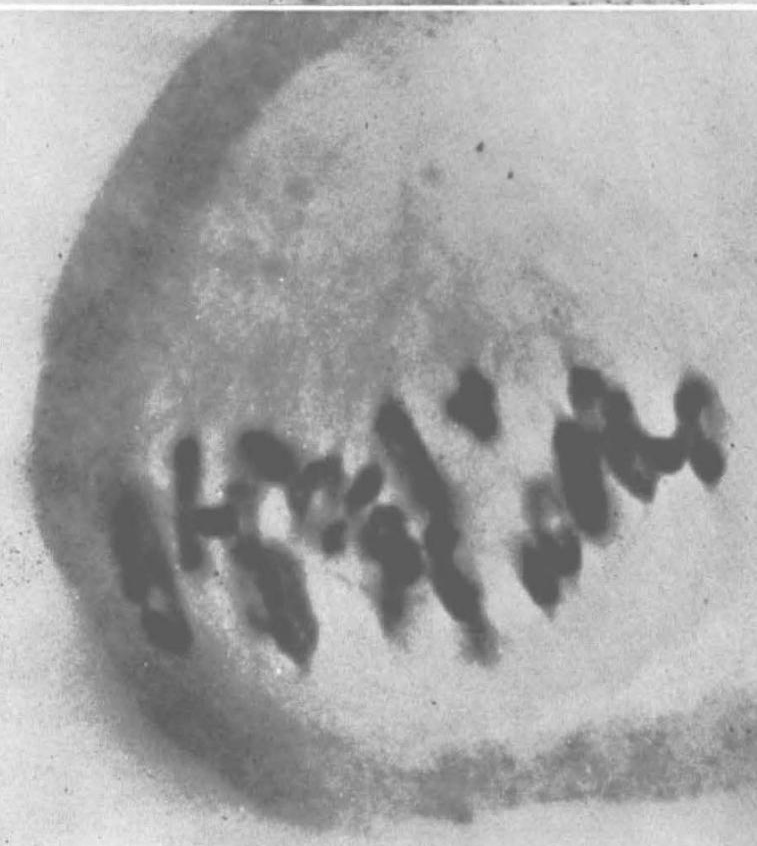


Plate II

FIgs. I and 2.-SD/SD. Anaphase I. Same cell at different foci. $\times c a .1500$.
FIG. $1 .-\mathrm{b}_{2}^{\mathrm{I}}$.
Fig. 2. $-2 \mathrm{f}$.

FIg. 3.-SD/SD. Anaphase I. $b_{1}^{\mathrm{r}}+$ If. Fig. 4.-Anaphase II. Cells with bridges $\times$ ca. 1500 . and fragments. $\times c a .700$. 


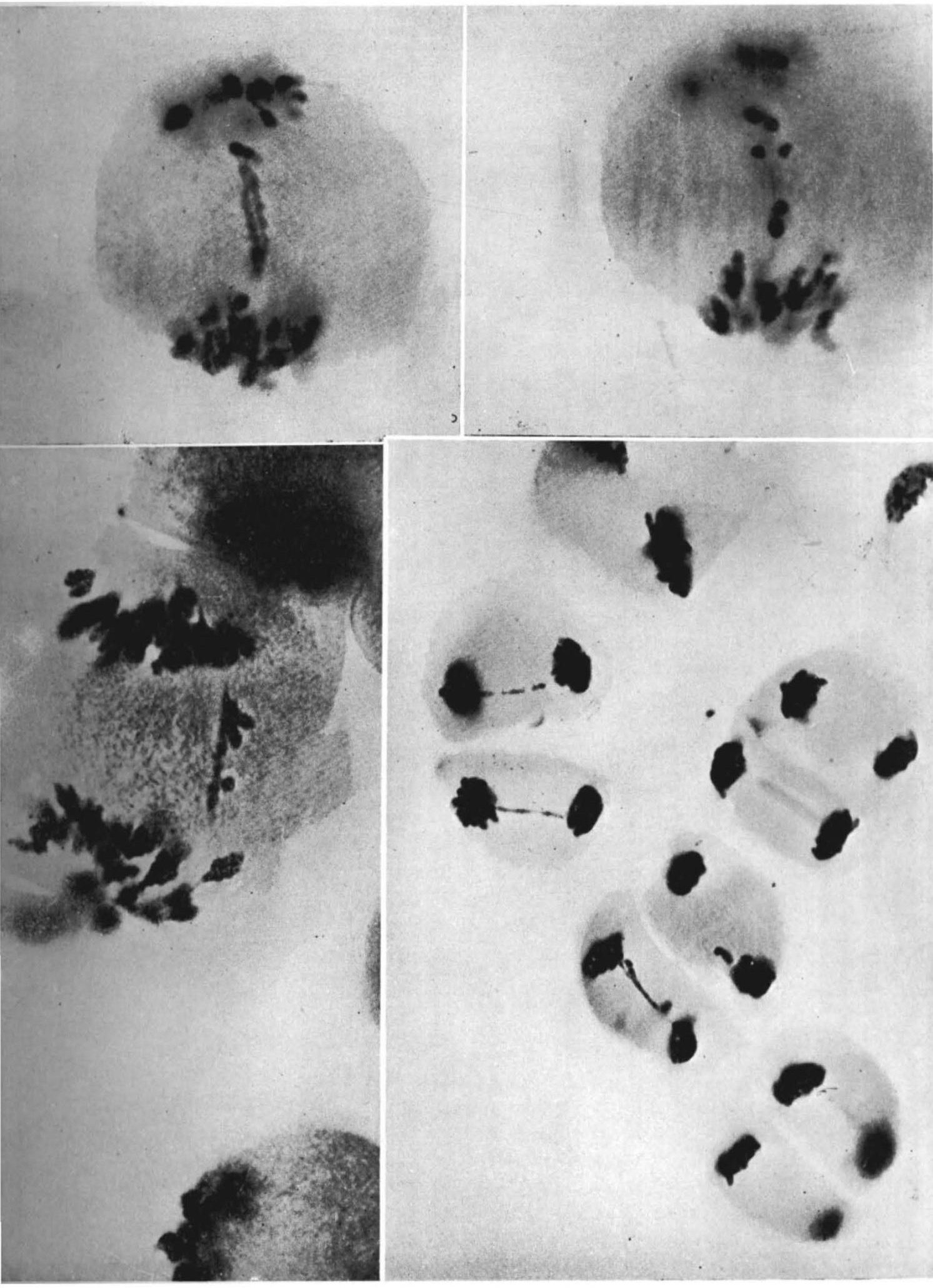

